\title{
Comparação entre módulos de deformação de concretos nacionais produzidos com agregados graúdos de diferentes origens mineralógicas
}

\author{
Comparison between deformation modulus of \\ national concretes made with coarse aggregates \\ from different mineralogical origins
}

Cleber Eduardo Fernandes Leal ${ }^{1}$, Guilherme Aris Parsekian ${ }^{2}$, Fernanda Giannotti da Silva Ferreira ${ }^{2}$, André Luis Christoforo ${ }^{2}$

\footnotetext{
${ }^{1}$ Aluno de doutorado. Programa de Pós-graduação em Engenharia Civil - PPGECiv - DECiv /UFSCar, CEP: 13565-905, São Carlos, SP, Brasil.

${ }^{2}$ Professor associado. Programa de Pós-graduação em Engenharia Civil - PPGECiv - DECiv /UFSCar, CEP: 13565-905, São Carlos, SP, Brasil.

e-mail: cleber.efl@hotmail.com,parsekian@ufscar.br, fgiannotti@ufscar.br, alchristoforo@ufscar.br
}

\begin{abstract}
RESUMO
Conhecer as propriedades do concreto é determinante para um dimensionamento seguro e eficiente, sobretudo em um cenário marcado pela adoção de elementos estruturais cada vez mais esbeltos e vãos cada vez maiores. Quando não determinados experimentalmente, os módulos estáticos de deformação dos concretos nacionais são estimados pelas equações contidas na ABNT NBR 6118. Em 2014, tais equações sofreram mudanças significativas. Novos coeficientes foram inseridos e, além da resistência característica à compressão do compósito, a natureza do agregado graúdo passou a ser considerada. Vale, porém, discutir o quão representativos têm sido, na prática, as equações empregadas e os coeficientes atribuídos a cada tipo de rocha. Soma-se a isso o fato de que os módulos de deformação do concreto são influenciados por inúmeros fatores, sendo a resistência à compressão do material apenas um deles. Partindo de uma reunião de resultados experimentais, este trabalho avaliou como os valores do módulo de deformação tangente inicial do concreto (Eci) têm se comportado com o uso de agregados graúdos distintos e provenientes de diferentes regiões do país. A influência dos parâmetros relação água/cimento $(\mathrm{A} / \mathrm{C})$, consistência e massa específica da mistura também foi investigada, bem como a afinidade dos resultados obtidos com a versão de 2014 da NBR 6118, com algumas de suas versões anteriores, e códigos estrangeiros. Como resultados, os dois modelos estatísticos obtidos para estimar Eci em função da relação A/C, abatimento, massa específica e resistência à compressão dos concretos aos 28 dias apresentaram precisão entre $70 \%$ e $90 \%$. Entre as propriedades abordadas, a massa específica $(\rho)$ foi a que mais influenciou os valores de $E c i$. Os demais modelos obtidos se mostraram mais conservadores que o os modelos normativos para concretos contendo calcário. Para agregados de granito/gnaisse todos modelos foram equivalentes. Para o basalto, os modelos normativos se apresentaram mais conservadores que os encontrados aqui.
\end{abstract}

Palavras-chave: Concreto. Propriedades Mecânicas. Módulos de deformação. Agregado graúdo.

\section{ABSTRACT}

Knowing the concrete properties is crucial for a safe and efficient design, mainly in a scenario marked by the adoption of increasingly slender elements and increasingly large spans. When not experimentally determined, the static deformation modules of national concretes are estimated by the equations contained in ABNT NBR 6118. In 2014, such equations underwent significant changes. New coefficients were inserted and, in addition to the characteristic resistance to compression of the composite, the nature of the coarse aggregate came to be considered. However, it is worth discussing how representative the equations used and the coefficients attributed to each type of rock have been in practice. Added to this is the fact that the concrete deformation 
modules are influenced by numerous factors, the compressive strength of the material being only one of them. Starting from a set of experimental results, this work evaluated how the values of the initial tangent deformation modulus of concrete $(E c i)$ have behaved with different coarse aggregates, from different regions in the country. The influence of the parameters water/cement (W/C) ratio, slump, density also have been investigated, as well as the affinity of the results obtained with the current 2014 version of NBR 6118, with some of its previous versions, and foreign codes were also investigated. As results, the two models obtained to estimate Eci as a function of the W/C ratio, slump, density and concrete compressive strength at 28 days showed precision between $70 \%$ and $90 \%$. Among the properties addressed, the density $(\rho)$ was the one that most influenced the Eci values. The other models obtained were more conservative than the normative models for concretes containing limestone. For granite/gneiss aggregates all the models were equivalent. For basalt, the normative models were more conservative than those found here.

Keywords: Concrete. Mechanical properties. Deformation Modulus. Coarse aggregate.

\section{INTRODUÇÃO}

A necessidade pela otimização dos projetos, relacionada, entre outros fatores, ao melhor aproveitamento das áreas disponíveis, tem impulsionado a adoção de elementos cada vez mais esbeltos e vãos cada vez maiores, alterando significativamente a concepção e a execução das estruturas de concreto. Segundo KALRA e MEHMOOD [1], os espaços restritos, a rápida urbanização e o crescimento da população demandam, ao mesmo passo, por edifícios mais altos e melhores desempenhos dos concretos empregados. Quanto às propriedades do concreto, GIRARDI et al. [2] pontuam que os módulos de deformação do material sempre receberam menos atenção que a propriedade de resistência à compressão no que se refere às obras comuns, concebidas em estruturas reticuladas de concreto armado, de vãos pequenos e emprego dos concretos convencionais. Com a recente tendência de aumento nos vãos e na altura das edificações, índices atípicos de esbeltez têm sido alcançados. Estruturas particulares como torres de telefonia ou para suporte de turbinas eólicas passam a requerer maior precisão e compatibilidade quando confrontadas as deformações atingidas e estabelecidas nos projetos.

De acordo com PIASTA et al. [3], as evoluções nas propriedades dos materiais de construção também permitem reduzir as seções transversais dos elementos estruturais. Porém, com seções reduzidas, a rigidez dos elementos também é minorada, fazendo com que os esforços solicitantes e as deformações (deflexão e abertura de fissuras) cresçam na mesma magnitude. Além disso, aumentos na propriedade de resistência à compressão do concreto por exemplo, não implicam em aumentos dos módulos de deformação do material de maneira proporcional [4]. ZHOU et al. [5] afirmam que aumentos de 50 para $100 \mathrm{MPa}$ na resistência à compressão do concreto correspondem a aumentos de apenas $20 \%$ no módulo de elasticidade do material, mantendo-se o mesmo tipo e quantidade de agregados presentes nas misturas. Dessa forma, análises cautelosas, que vão além da resistência à compressão e que permitam aproximar ao máximo os projetos estruturais das situações reais, são necessárias [6].

Segundo MARCHI [4], analisar deformações em uma estrutura é importante quando se objetiva evitar danos aos sistemas de vedações, deslocamentos perceptíveis/nocivos ao conforto do usuário, e ainda garantir o prolongamento de sua vida útil. Tais investigações só são possíveis conhecendo o comportamento do material sob carregamento, o qual está atrelado a propriedades mecânicas como os módulos de deformação.

A versão de 2014 da NBR 6118 [7] passou a considerar a origem do agregado graúdo no cálculo do módulo de elasticidade do concreto, além de incluir em seu escopo concretos com classes de resistência característica à compressão $(f c k)$ de até $90 \mathrm{MPa}$. Assim, na equação que, para ausência de ensaios, estima o módulo de elasticidade em função de $f c k$, foi incluído um coeficiente $\alpha \mathrm{E}$, cujo valor varia de 0,7 a 1,2 de acordo com o tipo de rocha (basalto, diabásio, granito, gnaisse, calcário ou arenito).

A principal discussão remete à representatividade de tais equações e dos valores adotados para $\alpha \mathrm{E}$, sobretudo ao 1,2 atribuído ao basalto, que traduz um aumento de $20 \%$ em relação aos valores de módulo calculados pela versão de 2007 da NBR 6118 [8]. Com resultados obtidos em estudos experimentais geralmente inferiores ao que a versão de 2014 (vigente) da NBR 6118 [7] propõe, questiona-se o coeficiente em questão, como se o mesmo estivesse superestimando o comportamento dos concretos em comparação com o que se verifica na prática $[9,10]$. Segundo SANTOS et al. [11], a utilização de coeficientes nas normativas que representem os tipos litológicos de tochas nem sempre resultam em valores compatíveis com os reais, uma vez que, diferentes jazidas podem produzir diferentes materiais.

Partindo de uma reunião de estudos experimentais, este trabalho visa avaliar de que maneira os valores do módulo de deformação tangente inicial (conhecido por módulo de elasticidade do concreto) têm se com- 
portado com o uso de agregados graúdos distintos e provenientes de diferentes regiões do país. Investiga-se ainda a influência de parâmetros como relação $\mathrm{A} / \mathrm{C}$, consistência da mistura, massa específica na propriedade em questão, além da afinidade dos resultados com modelos normativos de predição.

\section{OS MÓDULOS DE DEFORMAÇÃO DO CONCRETO}

VASCONCELOS e GIAMMUSSO [12] destacam que o conceito de elasticidade não depende de um comportamento linear, embora muitas vezes seja assim interpretado. Na ausência de deformações residuais quanto extinto o carregamento, o material é denominado "elástico". Se, além disso, o diagrama for retilíneo tanto para o aumento quanto para o decréscimo de tensão, o material é considerado "elástico linear". Somente neste caso pode-se falar em módulo de elasticidade (Figura 1a). Assim, é preferível o uso do termo "módulo de deformação" ao invés de adotar "módulo de elasticidade" de maneira generalizada. Por extensão e por comodidade, passou-se a falar em módulo de elasticidade mesmo com diagramas curvos (Figura 1b) e com diagramas diferentes no carregamento e no descarregamento (Figura 1c), como é o caso do concreto (Figura 1d).

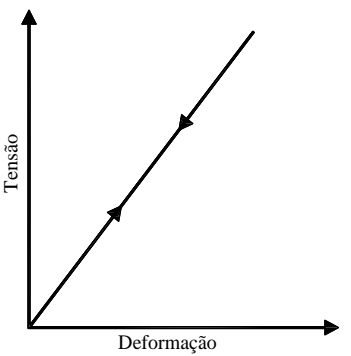

(a) Linear e elástico

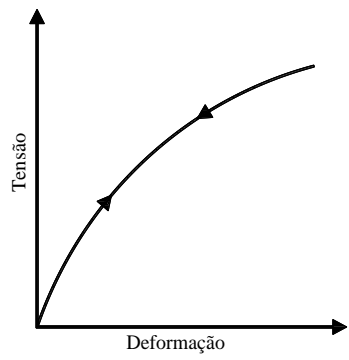

(b) Não linear e elástico

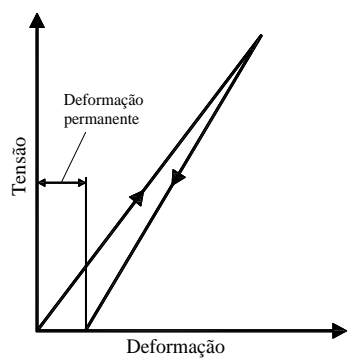

(c) Linear e não elástico

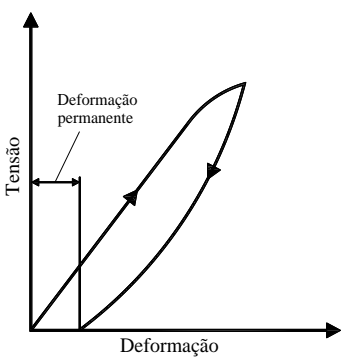

(d) Não linear e não elástico

Figura 1: Comportamentos possíveis do diagrama tensão-deformação [13].

Conforme posto pela versão de 2014 da NBR 6118 [7], os módulos de deformação estáticos do concreto devem ser obtidos pela análise da curva tensão-deformação resultante do ensaio prescrito na NBR 8522 [14]. A denominação "estático", por sua vez, é utilizada devido ao fato de que os módulos de deformação também podem ser estimados por meio de ensaios dinâmicos e não destrutivos, onde o concreto tem, por exemplo, a propriedade inferida segundo o tempo e a forma como ondas ultrassônicas percorrerem seu interior. Segundo MEHTA e MONTEIRO [15], os módulos dinâmicos de deformação do material têm maior aplicação na análise de estruturas submetidas a ações sísmicas ou cargas de impacto. Os módulos dinâmicos não serão objetos deste estudo.

O módulo de deformação secante (Ecs) é a propriedade do concreto cujo valor numérico corresponde ao coeficiente angular da reta secante ao diagrama tensão-deformação específica, passando pelos seus pontos A e $\mathrm{B}$ correspondentes respectivamente à tensão mínima $\sigma \mathrm{A}=0,5 \mathrm{MPa}$ e à tensão $\sigma \mathrm{B}$, considerada no ensaio (Figura 1a) [14]. Em geral, trabalha-se com $\sigma B$ igual à $40 \%$ da tensão de ruptura do concreto $(f c)$, obtida no ensaio de resistência à compressão [16].

O módulo de deformação tangente inicial (Eci), conhecido como "módulo de elasticidade do concreto", ou ainda "módulo de Young", corresponde ao módulo de deformação cordal entre $\sigma \mathrm{A}=0,5 \mathrm{MPa}$ e $30 \%$ da tensão última $(f c)$ [14], tal como apresentado pela Figura 2b. MEHTA e MONTEIRO [15] definem "módulo de elasticidade do concreto" como a relação entre a tensão aplicada e a deformação instantânea, dentro de um limite proporcional assumido. 


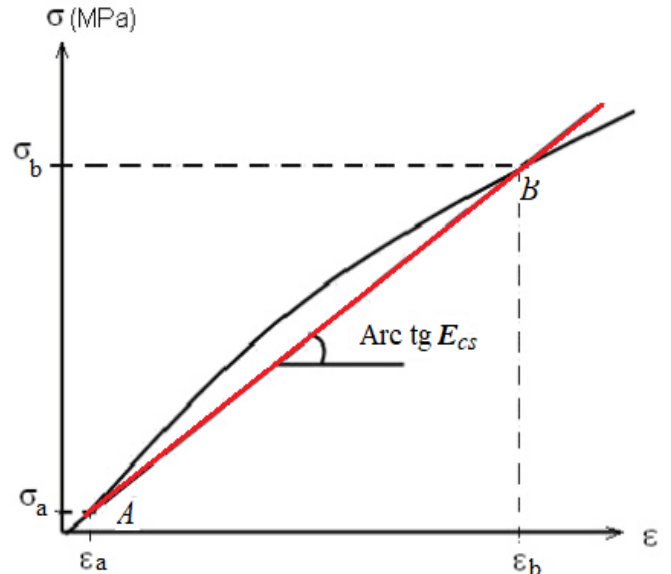

a) Módulo de deformação secante

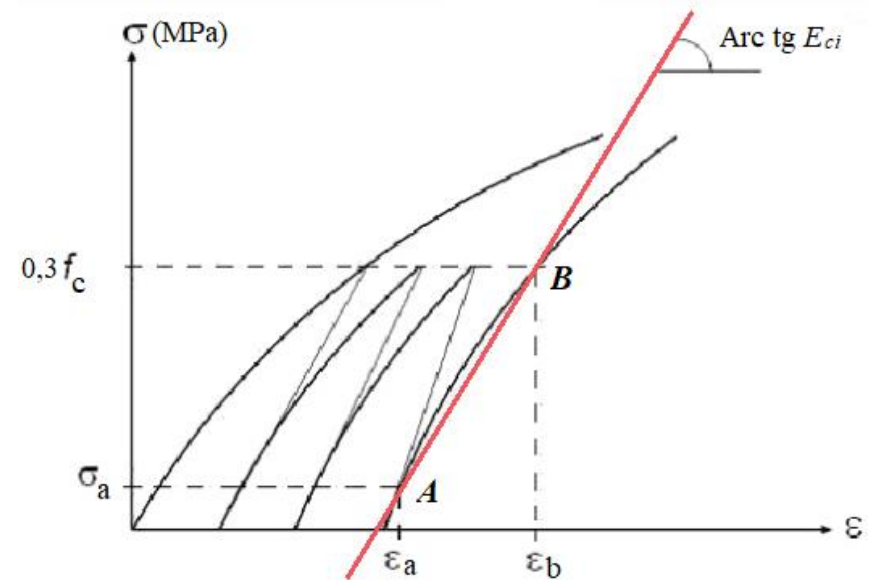

b) Módulo de deformação tangente inicial

Figura 2: Representação dos módulos de deformação do concreto [14].

Na prática, uma distinção arbitrária é realizada: a deformação resultante da aplicação das cargas de projeto é considerada elástica (deformação elástica inicial), e o subsequente aumento de deformação mantida a tensão é atribuído à fluência do material [17]. O alívio de tensões associado à fluência tem importantes explicações no comportamento das estruturas de concreto armado e protendido [16].

As três primeiras curvas no diagrama da Figura $2 \mathrm{~b}$ correspondem aos ciclos de carregamento e descarregamento exigidos pela NBR 8522 [14] antes que a medição das deformações seja realizada de fato. Segundo NEVILLE [13], os ciclos de pré-carregamento são aplicados para que o efeito da fluência do concreto não interfira nos resultados do módulo tangente e nem na instalação dos medidores de deformação. De acordo com BROOKS [17], a área compreendida entre as curvas de carregamento e descarregamento recebe o nome de "histerese". Representa a energia de deformação irreversível (fluência, microfissuração), que, junto à não linearidade do diagrama, tende a ser reduzida após subsequentes ciclos de carga-descarga. Estabelecer uma tensão mínima $\left(\sigma_{\mathrm{A}}\right)$, por sua vez, visa impedir que o corpo de prova se mova durante o ensaio [13].

O módulo de elasticidade do concreto se configura como uma propriedade dependente de vários fatores, entre estes: proporções volumétricas, tamanhos, formas e módulo dos agregados; consistência da mistura; condições de cura, idade do concreto, e parâmetros de ensaio [13, 15, 16]. SOUZA et al. [18] destacam o módulo de elasticidade como propriedade fundamental à obtenção de tensões entre o concreto e aço em construções de concreto armado e protendido, contribuindo também para cálculo das tensões resultantes de retração e recalques nas estruturas. CABRAL [19] reitera a afirmação feita por MARCHI [4] de que aumentos na resistência à compressão do concreto não refletem em aumentos no módulo na mesma magnitude, ao constatar em seu estudo experimental, que o módulo de elasticidade do concreto é uma propriedade bem menos sensível ao grau de hidratação do cimento (crescimento com a idade) que a resistência à compressão.

Segundo HELENE [16], a resistência à compressão é apenas uma das variáveis que interferem nos resultados de módulo de elasticidade do concreto. A relação pasta/argamassa/agregados graúdos assim como a natureza dos agregados graúdos exercem muita, quiçá maior, influência que a resistência. MONTEIRO et al. [20] afirmam que o módulo elástico do material depende, sobretudo, da aderência entre a matriz (pasta de cimento) e os agregados que a mesma envolve. Para HELENE [16], o módulo de elasticidade do concreto é uma variável difícil de ser medida e, por conta da grande sensibilidade à dosagem, tende a fornecer grande variabilidade nos resultados, mesmo quando mantidos os mesmos materiais.

\section{FATORES QUE INFLUENCIAM A RELAÇÃO TENSÃO/DEFORMAÇÃO DO CONCRETO}

Embora seja um material compósito, muitas características do concreto não seguem as regras das misturas. Se testados separadamente sob cargas de compressão, ambos, agregado e pasta de cimento hidratada apresentarão rompimento elástico, ou seja, até o momento da falha fornecerão deformações proporcionais às tensões aplicadas e reversíveis com a extinção do carregamento. Já o concreto como o conjunto, não conta com tal linearidade, exibindo deformações permanentes e um rompimento inelástico [15]. O comportamento distinto para cada uma das fases do concreto separadamente e do material compósito pode ser melhor entendido com base na Figura 3. 


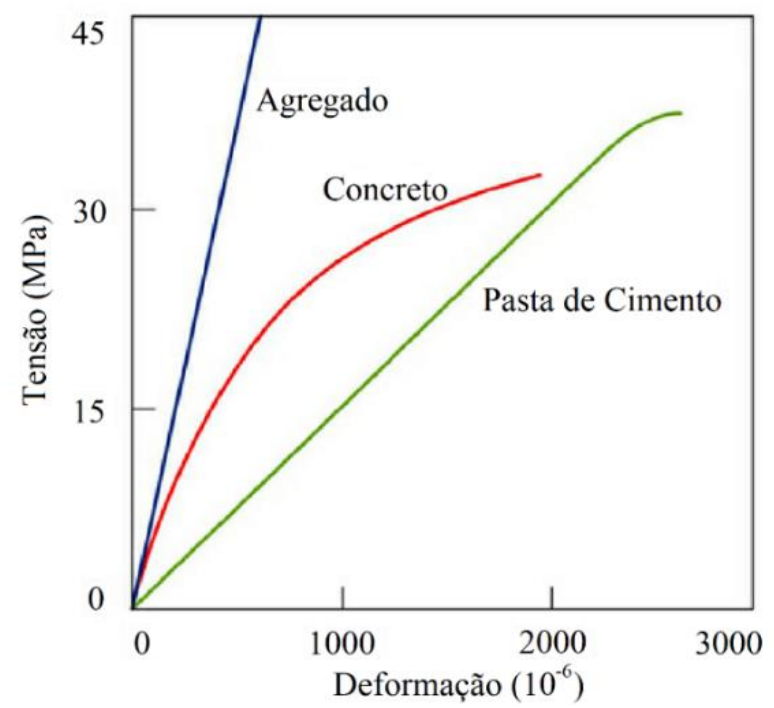

Figura 3: Diagrama tensão-deformação na compressão para o concreto e suas fases [15].

\subsection{Microfissuração na interface pasta-agregado}

Segundo NEVILLE [13], o comportamento diverso verificado para a curva do concreto (Figura 3) é atribuído ao desenvolvimento de microfissuras de aderência nas regiões de interface entre os agregados e a pasta de cimento hidratada. Com a microfissuração na interface agregado-matriz há a redução da área efetiva resistente à carga aplicada, de modo que a tensão local passe a ser maior do que a tensão nominal, baseada na seção total do elemento. Assim, as deformações no concreto aumentam em maior velocidade que a tensão, fazendo com que o diagrama tensão-deformação passe a se curvar.

Para MEHTA e MONTEIRO [15], as fissuras podem existir já mesmo antes da aplicação de uma carga externa, uma vez que, as fases do concreto são dotadas de propriedades mecânicas distintas, provocando a ocorrência de deformações diferenciais na zona de encontro entre os materiais. KALRA e MEHMOOD [1] confirmam a diferença entre os módulos de deformação do agregado e da pasta de cimento como a causa primária da microfissuração no concreto. Além disso, apontam a retração diferencial entre essas duas fases como principal responsável pela baixa resistência à tração do compósito. Estas fissuras iniciais dependem, dentre outros fatores, das características de exsudação e do histórico de cura do concreto [15].

Quando o concreto é submetido à compressão a fissuração progride. Inicialmente todo o carregamento é absorvido pelo agregado, fase mais rígida. À medida que o agregado se deforma, este vai transferindo parte da carga para a pasta de cimento, que começa a se destacar do agregado [12].

\subsection{Frações volumétricas, relação água/cimento e característica dos agregados}

Como o módulo de elasticidade do agregado geralmente é maior que o da pasta de cimento hidratada, maiores teores de agregado significam maiores valores para o módulo dos concretos obtidos [13]. COUNTO [21] avaliou o efeito isolado do módulo de elasticidade de diferentes agregados graúdos no módulo de elasticidade dos concretos produzidos. $\mathrm{O}$ autor verificou que as deformações aumentavam à medida que o módulo do agregado diminuía, além de confirmar a intensidade dessa variação como função teor de agregados na mistura.

STOCK et al. [22] investigaram propriamente os efeitos do aumento no volume de agregados sobre o módulo de elasticidade de concretos convencionais. Ao elevar de 20 a $80 \%$ a concentração dos agregados nos traços, o autor observou aumentos gradativos nos módulos dos concretos, o que ocorreu com maior intensidade para os teores acima de $60 \%$ em volume. NEVILLE [23] destaca, porém, que no caso de concretos de alta resistência (onde a pasta de cimento possui rigidez extremamente elevada) ou concretos produzidos com agregados leves (cujos módulos são menores), o volume de agregados na mistura não interfere da mesma maneira na relação tensão-deformação do material, uma vez que a diferença entre os módulos do agregado e da pasta de cimento é minimizada. Além disso, essa equidade faz com que a concentração de tensões na interface agregado-pasta seja reduzida, e o concreto resultante passa então a apresentar um diagrama mais line- 
ar, com provável intensificação do comportamento frágil.

WU et al. [24] afirmam que nos concretos de alta resistência, onde as relações $\mathrm{A} / \mathrm{C}$ não ultrapassam 0,4 , a resistência do próprio agregado, da argamassa e de sua interface com a matriz passam a ser equivalentes. Por esse motivo, o tipo do agregado graúdo se torna determinante na resistência e deformabilidade do material [1]. Agregados mais rígidos tendem a fornecer concretos mais rígidos. Alguns autores confirmaram tal afirmação ao obterem valores maiores para o módulo de elasticidade na flexão em concretos contendo agregados graúdos de basalto e de andesito (mais rígidos) em relação aos módulos dos concretos contendo agregados de granito [25, 26]. AÏTCIN e MEHTA [27] complementam que, em concretos com resistências superiores à $40 \mathrm{MPa}$, particularmente acima de $80 \mathrm{MPa}$, as relações $\mathrm{A} / \mathrm{C}$ residem em torno de 0,2 a 0,3 . Nesse caso nem a pasta de cimento e nem a ZTI são mais os pontos fracos do compósito, mas a mineralogia e resistência do agregado graúdo é que passam a ser os fatores limitantes na resistência do material.

YILDIRIM e SENGUL [28] ensaiaram espécimes cilíndricos (150 x $300 \mathrm{~mm})$ de 60 traços de concreto produzidos com agregados de dolomita, calcário, basalto e quartzo. Investigou-se a influência dos fatores A/C, tipo e dimensão máxima dos agregados no módulo de elasticidade dos concretos. Nos resultados, os autores observaram reduções no módulo de elasticidade com o aumento da relação A/C. Quanto ao tipo de agregado, concretos contendo agregados calcários apresentaram os menores módulos de elasticidade, enquanto os demais tipos de agregado forneceram resultados semelhantes, mesmo variando a relação A/C. Os autores atribuem tal resultado à menor rigidez do calcário em relação aos demais agregados. Para o tamanho dos agregados, notou-se que reduções na dimensão máxima de $32 \mathrm{~mm}$ para 16 ou $8 \mathrm{~mm}$ não alteraram substancialmente o módulo de elasticidade dos concretos. Porém, nas misturas contendo agregados menores que isso $(4 \mathrm{~mm})$ a propriedade decresceu. Segundo os pesquisadores, para um mesmo teor de agregados, reduções no tamanho das partículas tendem a elevar sua superfície de contato na mistura. Como resultado, a área da interface entre agregado e a pasta de cimento hidratada também é ampliada, reduzindo o módulo de elasticidade do compósito. NEVILLE [23] afirma que em concretos normais e leves, a zona de transição na interface (ZTI) pasta-agregado corresponde ao elo mais fraco na microestrutura do material.

ZHOU et al. [29] também investigaram a influência do volume, tipo e dimensão máxima do agregado graúdo, e relação A/C no módulo de elasticidade de corpos-de-prova prismáticos $(100$ x 100 x $300 \mathrm{~mm}) \mathrm{de}$ concretos normais, testados em 12h, 1, 2, 3, 7, 14 e 28 dias de idade. Os autores confirmaram aumentos no módulo de elasticidade do material à medida que as frações volumétricas dos agregados foram elevadas, apontando o volume de agregado graúdo na mistura como o fator mais influente na propriedade. Alterações na dimensão máxima dos agregados não afetaram substancialmente o módulo dos concretos. Quanto ao tipo do agregado, agregados graúdos com módulos maiores também originaram concretos com maiores valores de módulo de elasticidade. Sobre a relação A/C, maiores valores para a relação originaram menores valores de módulo.

GIRARDI et al. [2] avaliaram o efeito isolado do volume da pasta de cimento no módulo de deformação de seis traços distintos de concreto. Para tal, a relação $\mathrm{A} / \mathrm{C}$ foi mantida constante e a consistência necessária obtida com aditivos plastificantes. Os testes foram realizados aos 14, 28 e 150 dias de idade das amostras. Nos resultados, os pesquisadores observaram que, reduções de 50,2\% para $22,3 \%$ no volume da pasta de cimento refletiram em maiores quantidades de agregados (componentes mais rígidos na mistura) e, consequentemente, aumentos de 30,5\%, 33,5\% e 28,8\% nos valores dos módulos de elasticidade dos concretos aos 14,28 e 150 dias, respectivamente. Os autores destacam ainda que, misturas com maiores volumes de pasta apresentaram menores módulos mesmo tendo resistências à compressão ligeiramente maiores, o que incita o questionamento acerca da real precisão de modelos teóricos que estimam o do módulo do concreto em função da resistência à compressão do material como única variável.

HONG et al. [30] estudaram a influência que o tipo de agregado graúdo (calcário, basalto e quartzito) e a rugosidade de sua superfície exercem na aderência da interface agregado graúdo-argamassa, em concretos submetidos aos esforços de compressão e tração diametral. Nos resultados, observaram que a resistência à tração e ao cisalhamento na interface tende a aumentar com o aumento na rugosidade do agregado, até atingir uma constância. Os agregados de quartzito forneceram as maiores resistências na região, seguidos do calcário e do basalto.

NEVILLE [23] define a microestrutura do concreto como sendo composta por pelo menos três fases: agregado, pasta de cimento hidratada e a ZTI entre ambos. YILDIRIM e SENGUL [28] afirmam que quando a relação A/C é elevada, os poros capilares do concreto aumentam e, consequentemente, a ZTI se torna mais porosa e mais suscetível à microfissuração. Por consequência, o módulo de elasticidade do material descresse. Em misturas com relações $\mathrm{A} / \mathrm{C}$ menores, a zona de transição é mais forte e, à medida que ocorre o aumento de tensão no concreto, sua curva de tensão-deformação tende a exibir maior linearidade no trecho ascendente. 
SCRIVENER e GARTNER [31] apontam a maior porosidade como sendo uma característica intrínseca da ZTI, e consequência de três fatores principais. O primeiro consiste na ausência de grãos anidros (não hidratados) de cimento na região, causada pela própria barreira física promovida pelo agregado de maior dimensão. O segundo fator corresponde à presença de partículas menores na interface que, em função da maior superfície de contato, hidratam rapidamente deixando espaços vazios. O terceiro fator é atribuído à diferença na dureza das superfícies do agregado e da pasta de cimento, que, durante eventual polimento/regularização do concreto, pode originar erosões na região da interface.

ZIJIAN et al. [32] estudaram, especificamente, os efeitos da dimensão máxima do agregado graúdo de calcário $(5,10,20$ e $30 \mathrm{~mm})$, da relação $\mathrm{A} / \mathrm{C}(0,23 ; 0,35$ e 0,53$)$ e do tempo de cura (3 a 90 dias) na ZTI pasta-agregado dos concretos produzidos. Notaram que tanto a porosidade quanto a espessura da ZTI com aumento na relação $\mathrm{A} / \mathrm{C}$. A presença de grãos anidros de cimento, sobretudo na região próxima à superfície do agregado graúdo, foi reduzida com aumento na relação A/C. Aumentos na dimensão do agregado graúdo, também refletiram em maiores espessuras da ZTI. Quanto maior o tempo de cura, menor foi a espessura da ZTI.

\subsection{Consumo de cimento e presença de adições minerais}

Em seu estudo sobre dosagem de concretos convencionais, MONTEIRO et al. [20] testaram seis diferentes traços, variando proporções entre os agregados, consistência e relação A/C. Concluíram que, quando mantida a mesma consistência para a mistura, aumentos na quantidade de cimento refletem em aumentos nos módulos de elasticidades do material (Figura 4a). Os autores explicam que quando o slump é mantido constante, o teor do ligante é elevado com a redução da relação $\mathrm{A} / \mathrm{C}$, dando origem a uma matriz mais rígida e resistente.

Os pesquisadores também testaram aumentos no teor de cimento fixando a relação A/C no valor de 0,5 e, nesse caso, notaram o contrário: o módulo de elasticidade dos concretos foi reduzido (Figura 4b). De acordo com os autores, quando mantida a relação $\mathrm{A} / \mathrm{C}$, aumentos no teor de cimento acarretam em reduções na quantidade de agregados, e como nos concretos normais os agregados possuem maior rigidez que a pasta de cimento, o módulo de elasticidade do concreto decresce.

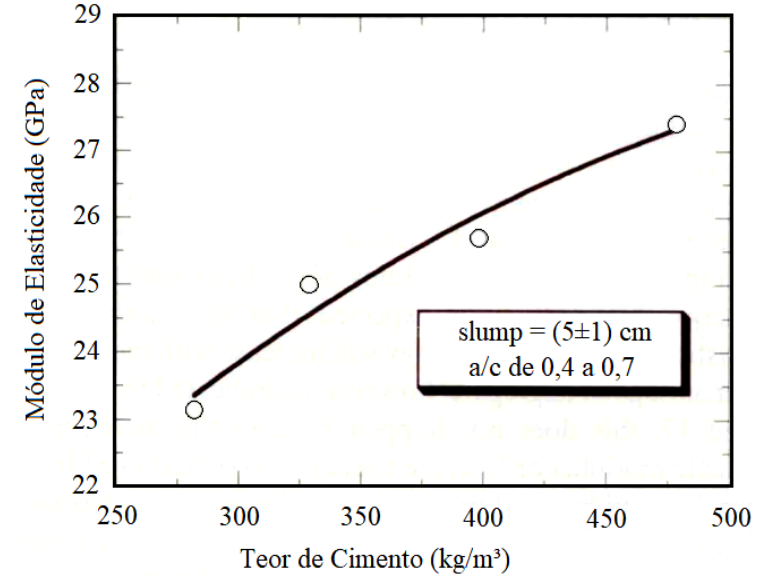

(a) Com slump constante

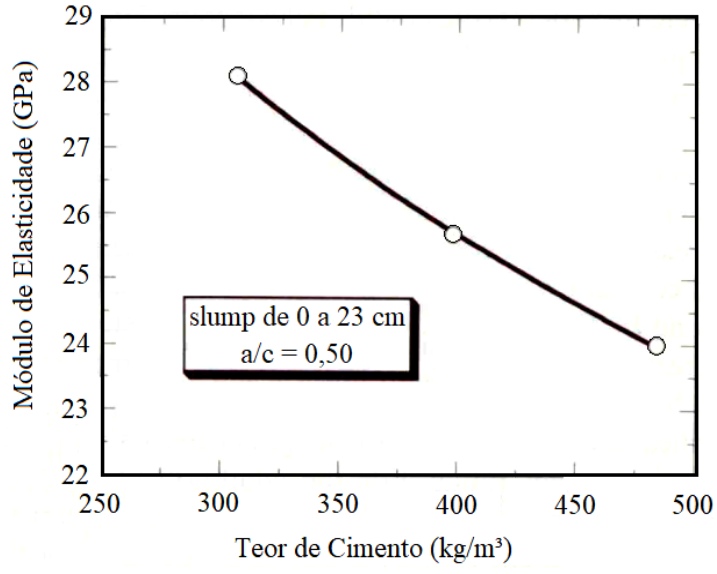

(b) Com relação $\mathrm{A} / \mathrm{C}$ constante

Figura 4: Influência do aumento do teor de cimento no módulo de elasticidade de concretos convencionais [20].

GIRARDI et al. [2], por sua vez, concluíram que, se mantida a mesma resistência à compressão, maiores consumos de cimento não refletiram em aumentos significativos nos módulos de elasticidade dos concretos estudados. YILDIRIM e SENGUL [28] adicionaram 17,5\%; 25\% e 33\% da massa de cimento em cinzavolante e não observaram mudanças significativas nos valores de módulo de elasticidade dos concretos obtidos.

PAULON et al. [33] investigaram a influência que a substituição parcial do cimento Portland por sílica ativa, cinza volante e pozolana natural (separadamente) exerceria nas resistências à tração e cisalhamento da ZTI. Para isso, metades de espécimes cilíndricos de granito $(4,5 \times 9 \mathrm{~cm})$ foram imersas em camadas de 2 $\mathrm{cm}$ de pasta de cimento contendo cada adição e testadas aos 7, 28 e 90 dias de idade. A sílica ativa foi a única adição que promoveu aumentos de resistência à compressão e à tração na pasta de cimento maiores que a amostra de referência dos 7 aos 90 dias. 
Quando isolados os efeitos na ZTI, a influência das adições foi mais expressiva. Dos 7 aos 90 dias, a sílica ativa elevou a resistência à tração na ZTI em 39\% (aumento da referência 20,7\%), contra 34,3\% na pasta de cimento (aumento da referência 27,4\%). A cinza volante elevou a propriedade na ZTI em $24 \%$, contra $21,1 \%$ na pasta de cimento. A pozolana aumentou a propriedade na ITZ em $16,4 \%$, contra $17,1 \%$ na pasta de cimento. Para a resistência ao cisalhamento dos 7 aos 90 dias, a sílica ativa aumentou a propriedade na ITZ em $32 \%$ (aumento da referência 26,4\%), contra $27,7 \%$ na pasta de cimento (aumento da referência $28,2 \%$ ). A cinza volante elevou a propriedade na ZTI em $20,8 \%$, contra $23,8 \%$ na pasta de cimento. A pozolana aumentou a propriedade na ITZ em 20,8\%, contra 20,3\% na pasta de cimento.

PAULON et al. [33] explicam que, além de maior porosidade em relação à matriz de cimento, a ZTI entre os agregados e a pasta apresenta as seguintes características microestruturais: precipitação de cristais maiores de hidróxido de cálcio - $\mathrm{Ca}(\mathrm{OH})_{2}$ e etringita $\left(\mathrm{C}_{6} \mathrm{AS}_{3} \mathrm{H}_{32}\right)$, e deposição dos cristais de hidróxido de cálcio com orientação preferencial próxima à superfície do agregado. Nesse sentido, adições minerais, como a sílica ativa, com grãos muito finos e de grande reatividade, permitem reduzir a porosidade na ZTI bem como o tamanho e quantidade do hidróxido de cálcio formado na região. As pozolanas, por sua vez, com partículas maiores tendem a não ser tão reativas.

\subsection{Velocidade no carregamento e outros aspectos de ensaio}

A relação entre tensão e deformação do concreto também depende do tempo de carregamento a que este é solicitado. De acordo com VASCONCELOS e GIAMUSSO [12], quando solicitado, os poros existentes no concreto se comprimem (ou se distendem, conforme o esforço solicitante) e tendem a produzir um fluxo da água e ar presentes. Se o carregamento for lento, há tempo para que o escoamento dos fluidos ocorra. Com carregamentos muito rápidos, as condições em que se processam tais escoamentos são diferentes e os resultados podem não ser os mesmos. NEVILLE [13] afirma que aumentando de 5 segundos para cerca de 2 minutos o tempo de carregamento, as deformações observadas chegam a ser cerca de $15 \%$ maiores. BROOKS [17] confirma que na compressão a relação de tensão-deformação do concreto é afetada pela taxa de carregamento, de tal forma que, quanto maior a taxa maior o valor do módulo de elasticidade e maior também a resistência à compressão, fazendo com que o diagrama se torne menos curvilíneo.

A condição de umidade do concreto também afeta o modo de elasticidade e a resistência à compressão do material. Espécimes molhados tendem a apresentar resistência à compressão menor e módulo de elasticidade maior que um espécime seco [13].

MONTIJA [34] avaliou a variabilidade nos resultados de módulo de elasticidade do concreto associada ao tipo de instrumento usado na medição de deformações. De quatro instrumentações distintas (compressômetro de um e dois relógios comparadores, strain-gage de colagem superficial e clip-gage), o autor concluiu que o clip-gage foi o meio mais preciso e o compressômetro de dois relógios o de maior variabilidade por este meio ser mais suscetível a erros sistemáticos e aleatórios entre cada medição.

ARAÚJO et al. [35] avaliaram a influência do tipo de medição na determinação do módulo de elasticidade do concreto e encontraram resultados distintos. Também testaram quatro tipos de medidores de deformação (compressômetro mecânico, extensômetro elétrico de colagem superficial, extensômetro elétrico de fixação externa e transdutor diferencial de variação linear - LVDT), além de variarem a classe de resistência do concreto e tamanho dos corpos de prova. Constatou-se a interferência significativa do meio de medição nos resultados. O LVDT, com leitura analógica, foi considerado o menos preciso, enquanto os dois medidores extensômetros elétricos tiveram leituras mais consistentes e menores coeficientes de variação. Para todas classes de resistência testadas, verificou-se que os corpos de prova cilíndricos de 100 x $200 \mathrm{~mm}$ apresentaram maior dispersão e média menor para o módulo em relação aos espécimes de 150 x $300 \mathrm{~mm}$.

MARTINS [36] mediu o módulo de elasticidade de 600 corpos de prova cilíndricos de concretos C25, C30 e C40, com agregado graúdo granítico da região de Goiânia-GO. Metade nas dimensões de 100 x 200 $\mathrm{mm}$ e a outra metade 150 × $300 \mathrm{~mm}$. Concluiu-se que o tamanho do corpo de prova interfere significativamente nos resultados da propriedade, sendo maiores os módulos dos corpos de prova com menores dimensões. Os principais fatores intervenientes nos módulos de deformação do concreto são sintetizados pelo organograma contido na Figura 4. 


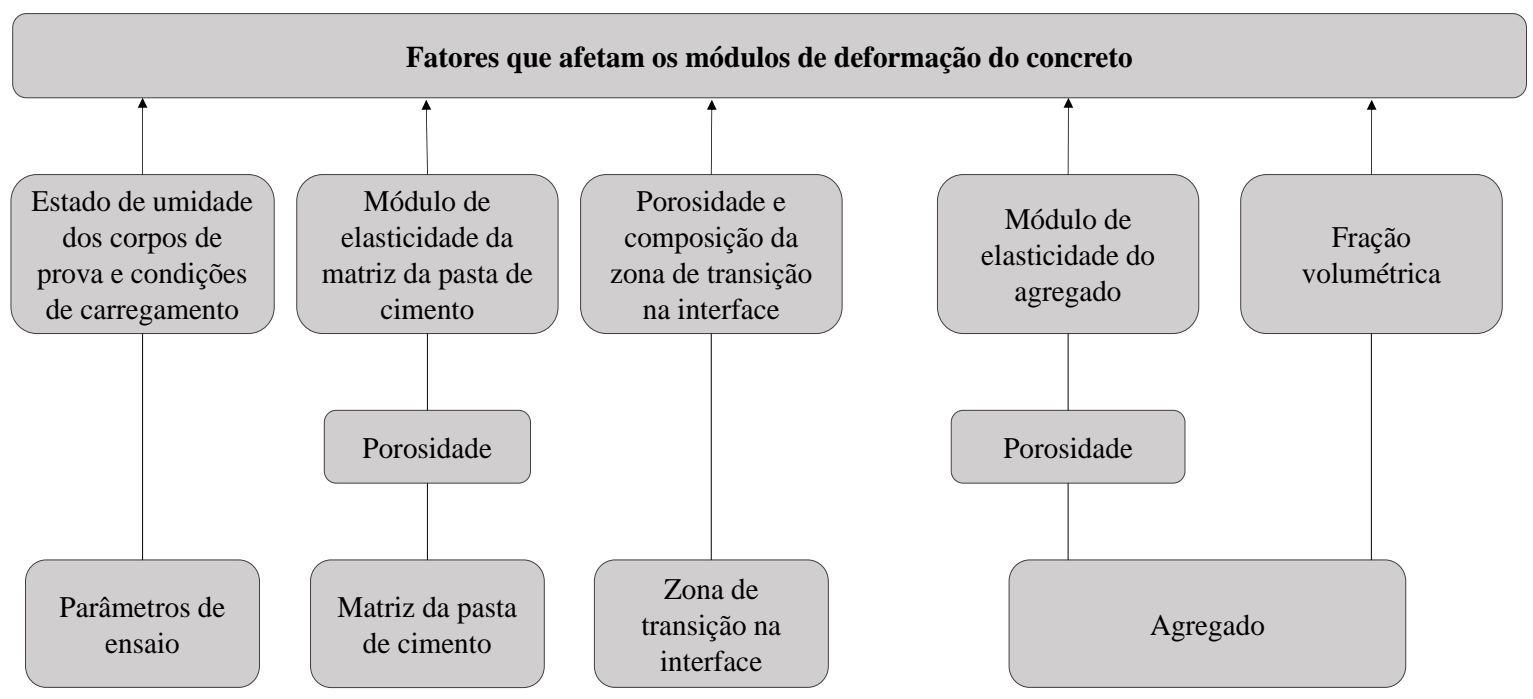

Figura 5: Fatores que interferem no módulo de elasticidade do concreto [15].

Quando não executados os ensaios, os módulos de deformação estáticos do concreto podem ser estimados por meio de expressões empíricas (Tabela 1), fundamentadas, principalmente, na correlação com outras propriedades físicas e/ou mecânicas do material. Algumas dessas equações constam como recomendações na normalização nacional e internacional. Em sua maioria, assumem a forma $\alpha f c^{\beta}$, sendo $f c$ a resistência à compressão do concreto (valor médio ou característico). Para critério de projeto, esses códigos admitem, via de regra, o mesmo valor dos módulos para o concreto solicitado tanto na tração quanto na compressão [37].

Tabela 1: Equações normativas para predição dos módulos de deformação do concreto.

\begin{tabular}{|c|c|c|c|}
\hline NORMA & ORIGEM & EQUAÇÕES & OBSERVAÇÕES \\
\hline $\begin{array}{c}\text { NB } 1 \text { (versão 1978) } \\
\text { [38] }\end{array}$ & Brasil & $\begin{array}{l}E_{c i}=6600 \sqrt{f c j} \\
f_{c j}=f_{c k}+3,5\end{array}$ & \multirow{4}{*}{$\begin{array}{l}E_{c i}=\text { Módulo de deformação } \\
\text { tangente inicial ou módulo de } \\
\text { elasticidade do concreto (em } \\
\text { MPa); } \\
f c j=\text { Resistência média de } \\
\text { dosagem do concreto à compres- } \\
\text { são (em MPa); } \\
f c k=\text { Resistência característica } \\
\text { à compressão do concreto (em } \\
\text { MPa); } \\
\alpha_{E}=\text { coeficiente do agregado } \\
\text { graúdo. Igual à } 1,2 \text { para basalto e } \\
\text { diabásio; } 1,0 \text { para granito, } 0,9 \\
\text { para calcário e } 0,7 \text { para arenito. }\end{array}$} \\
\hline $\begin{array}{c}\text { NB } 6118 \text { (versão } \\
\text { 2007) } \\
{[8]} \\
\end{array}$ & Brasil & $E_{c i}=5600 \sqrt{f c k}$ & \\
\hline NB 6118 (versão & & $\begin{array}{l}E_{c i}=\alpha_{E} \cdot 5600 \cdot \sqrt{f c k} \text { para concre- } \\
\text { tos com } f c k \text { entre } 20 \text { e } 50 \mathrm{MPa}\end{array}$ & \\
\hline $\begin{array}{c}\text { 2014) } \\
{[7]}\end{array}$ & Europa & $\begin{array}{l}E_{c i}=21,5 \times 10^{3} \cdot \alpha_{E} \cdot\left(\frac{f c k}{10}+1,25\right)^{1 /} \\
\text { para concretos com } f c k \text { entre } 55 \text { e } 90 \mathrm{MPa}\end{array}$ & \\
\hline $\begin{array}{c}\text { ACI } 318 \text { (versão } \\
\text { 2005) } \\
{[39]}\end{array}$ & $\begin{array}{l}\text { Estados } \\
\text { Unidos }\end{array}$ & $\begin{array}{l}E_{c}=4733 \cdot \sqrt{f_{c}^{\prime}} \text { para concretos com } \\
\text { valores normais de massa específica }\left(\omega_{c}\right) \text {; } \\
E_{c}=\omega_{c}^{1,5} \cdot 0,043 \cdot \sqrt{f_{c}^{\prime}} \text { para } \omega_{c} \\
\text { entre } 1440 \mathrm{e} 2480 \mathrm{~kg} / \mathrm{m}^{3} .\end{array}$ & $\begin{array}{l}E_{c}=\text { Módulo de deformação } \\
\text { secante medido de } \sigma=0 \text { a } \\
0,45 f c \text { (em MPa); } \\
f_{c}^{\prime}=\text { Resistência à compressão } \\
\text { do concreto aos } 28 \text { dias (em } \\
\text { MPa); } \\
\omega_{c}=\text { Massa específica do concre- } \\
\text { to }\left(\mathrm{kg} / \mathrm{m}^{3}\right) .\end{array}$ \\
\hline
\end{tabular}




\begin{tabular}{|c|c|c|c|}
\hline $\begin{array}{l}\text { ACI } 318 \text { (versão } \\
\qquad \begin{array}{l}\text { 2019) } \\
{[40]}\end{array}\end{array}$ & $\begin{array}{l}\text { Estados } \\
\text { Unidos }\end{array}$ & $\begin{array}{l}E_{c}=57000 \cdot \sqrt{f_{c}^{\prime}} \text { para concretos com } \\
\text { valores normais de massa específica }\left(\omega_{c}\right. \\
\text { )entre } 1440 \mathrm{e} 2560^{\mathrm{b}} \mathrm{kg} / \mathrm{m}^{3} \cdot \text {; } \\
E_{c}=\omega_{c}^{1,5} \cdot 33 \cdot \sqrt{f_{c}^{\prime}} \text { para } \omega_{c} \text { entre } 90 \\
\text { e } 160 \mathrm{lb} / \mathrm{ft}^{3} .\end{array}$ & $\begin{array}{l}E_{c}=\text { Módulo de deformação } \\
\text { secante (em Psi); } \\
f_{c}^{\prime}=\text { Resistência à compressão } \\
\text { do concreto (em Psi); } \\
\omega_{c}=\text { Massa específica do concre- } \\
\text { to }\left(\mathrm{em} \mathrm{lb} / \mathrm{ft}^{3}\right) \text {. }\end{array}$ \\
\hline $\begin{array}{c}f i b \text { MODEL } \\
\text { CODE CEB-FIP } \\
2010 \\
{[41]}\end{array}$ & Europa & $\begin{array}{l}E_{c i}=21,5 \times 10^{3} \cdot \alpha_{E} \cdot\left(\frac{f c m}{10}\right)^{1 / 3} \\
E_{c}=\alpha_{i} \cdot E_{c i} \\
\alpha_{i}=0,8+0,2 \cdot \frac{(f c m)}{88} \leq 1,0\end{array}$ & $\begin{array}{l}E_{c}=\text { Módulo secante (em MPa); } \\
f c m=\text { Resistência média à } \\
\text { compressão do concreto (em } \\
\text { MPa). Quando não conhecida, } \\
\text { estima-se } f c m=f c k+8 ; \\
\alpha_{E}=\text { Igual à } 1,2 \text { para basalto e } \\
\text { diabásio; } 1,0 \text { para granito, } 0,9 \\
\text { para calcário e } 0,7 \text { arenito. }\end{array}$ \\
\hline $\begin{array}{c}\text { EUROCODE 2- } \\
\text { EN 1992-1-1 } \\
\text { [42] }\end{array}$ & Europa & $\begin{array}{l}E_{c}=1,05 \cdot E_{c m} \\
E_{c m}=22 \cdot\left(\frac{f c m}{10}\right)^{0,3}\end{array}$ & $\begin{array}{l}E_{c}=\text { Módulo de elasticidade do } \\
\text { concreto (em MPa); } \\
E_{c m}=\text { Módulo de deformação } \\
\text { secante do concreto de } \sigma=0 \text { a } \\
0,40 f c(\mathrm{em} \mathrm{MPa}) .\end{array}$ \\
\hline $\begin{array}{c}\text { DIN - } 1045 \\
\text { [43] }\end{array}$ & Alemanha & $E_{c}=6170 \cdot \sqrt{f c}$ & $\begin{array}{l}E_{c}=\text { Módulo de elasticidade do } \\
\text { concreto (em MPa); } \\
f c=\text { Resistência à compressão } \\
\text { do concreto (MPa). }\end{array}$ \\
\hline
\end{tabular}

\section{MATERIAIS E MÉTODOS}

\subsection{Reunião dos resultados experimentais}

Inicialmente, um levantamento bibliográfico foi realizado, por meio do qual foram selecionados alguns estudos experimentais desenvolvidos com concretos contendo agregados graúdos provenientes de regiões distintas do país. As principais características dos trabalhos abordados são apresentadas na Tabela 2 e na Tabela 3.

Tabela 2: Dados gerais sobre os estudos experimentais escolhidos

\begin{tabular}{|c|c|c|c|c|c|c|}
\hline \multicolumn{2}{|c|}{ PESQUISA } & $\begin{array}{l}\text { NUNES } \\
{[44]}\end{array}$ & $\begin{array}{c}\text { PACHECO } \\
{[45]}\end{array}$ & $\begin{array}{c}\text { BARBOSA } \\
{[46]}\end{array}$ & $\begin{array}{c}\text { ALMEIDA } \\
{[47]}\end{array}$ & $\begin{array}{l}\text { LEAL } \\
{[48]}\end{array}$ \\
\hline \multirow{4}{*}{ MATERIAIS } & Agregado graúdo & $\begin{array}{c}\text { Gnaisse e } \\
\text { Sienito }\end{array}$ & Granito & $\begin{array}{c}\text { Micaxisto, } \\
\text { Granulito e } \\
\text { Basalto } \\
\end{array}$ & Gnaisse & Calcário \\
\hline & $\begin{array}{c}\text { Origem do agre- } \\
\text { gado }\end{array}$ & $\begin{array}{c}\text { Rio de } \\
\text { Janeiro-RJ }\end{array}$ & $\begin{array}{c}\text { Grande } \\
\text { Vitória-ES }\end{array}$ & Goiânia-GO & $\begin{array}{c}\text { Belo } \\
\text { Horizonte-MG }\end{array}$ & Brasília-DF \\
\hline & Cimento & $\begin{array}{c}\text { CP III RS e } \\
\text { CP III 40 RS } \\
\end{array}$ & CP III 40 RS & CP II F 32 & CP III 40 RS & CP V ARI RS \\
\hline & Aditivo & Sim & Sim & Sim & Não & Sim \\
\hline \multirow{2}{*}{$\begin{array}{l}\text { DOSAGEM } \\
\text { CONCRETO }\end{array}$} & Em central? & Sim & Sim & Não, betoneira. & Não, betoneira & Sim \\
\hline & Abatimento (mm) & 68 a 130 & 85 a 150 & $100 \pm 10$ & 90 & $100 \pm 20$ \\
\hline
\end{tabular}




\begin{tabular}{|c|c|c|c|c|c|c|}
\hline & $\begin{array}{c}\text { Relação } \\
\text { água/cimento }\end{array}$ & 0,40 a 0,60 & 0,403 a 0,694 & 0,50 a 0,84 & 0,45 a 0,65 & 0,48 a 0,91 \\
\hline & $\begin{array}{l}\text { fck nominal } \\
\text { (MPa) }\end{array}$ & 25,0 a 35,0 & 25,0 a 30,0 & 20,0 a 40,0 & 20,0 a 30,0 & 20,0 a 40,0 \\
\hline \multirow{6}{*}{ ENSAIOS } & Norma & \multicolumn{2}{|c|}{$\begin{array}{c}\text { ABNT NBR 5739: } 1994 \text { (com- } \\
\text { pressão) e ABNT NBR 8522: } \\
\text { 2003 (módulo) }\end{array}$} & $\begin{array}{c}\text { ABNT NBR } \\
\text { 5739: 1994 } \\
\text { (compressão) e } \\
\text { ABNT NBR } \\
\text { 8522: } 2007 \\
\text { (módulo) }\end{array}$ & $\begin{array}{c}\text { ABNT NBR } \\
\text { 5739: } 1994 \\
\text { (compressão) e } \\
\text { ABNT NBR } \\
\text { 8522: } 2003 \\
\text { (módulo) }\end{array}$ & $\begin{array}{c}\text { ABNT NBR } \\
\text { 5739: } 2007 \\
\text { (compressão) e } \\
\text { ABNT NBR } \\
\text { 8522: } 2008 \\
\text { (módulo) }\end{array}$ \\
\hline & $\begin{array}{c}\text { Idade de } \\
\text { ensaio (dias) }\end{array}$ & $3,7,14$ e 28 & 7,28 e 91 & 7 e 28 & 3,7 e 28 & $3,7,28$ e 91 \\
\hline & Tipo de cura & $\begin{array}{l}\text { Câmara úmida } \\
\text { até } 48 \mathrm{~h} \text { antes } \\
\text { do ensaio, } \\
\text { exceto para } \\
\text { ensaios aos } 3 \\
\text { dias de idade. }\end{array}$ & \multicolumn{2}{|c|}{$\begin{array}{l}\text { Câmara úmida, das } 24 \mathrm{~h} \text { de } \\
\text { idade até data de ensaio. }\end{array}$} & $\begin{array}{c}\text { Câmara úmida } \\
23^{\circ} \pm 3\end{array}$ & $\begin{array}{l}\text { Cura úmida até } \\
\text { a retificação } \\
( \pm 2 \mathrm{~h} \text { antes do } \\
\text { ensaio }) .\end{array}$ \\
\hline & $\begin{array}{l}\text { Geometria dos } \\
\text { corpos-de-prova }\end{array}$ & \multicolumn{3}{|c|}{$\begin{array}{l}\text { Cilíndrico } \\
15 \times 30 \mathrm{~cm}\end{array}$} & \multicolumn{2}{|c|}{$\begin{array}{l}\text { Cilíndrico } \\
10 \text { x } 20 \mathrm{~cm}\end{array}$} \\
\hline & $\begin{array}{l}\text { Tratamento da } \\
\text { superfície } \\
\text { de trabalho }\end{array}$ & \multicolumn{3}{|c|}{ Capeamento } & - & Retificação \\
\hline & $\begin{array}{l}\text { Medidores de } \\
\text { deformação }\end{array}$ & $\begin{array}{l}\text { Compressôme- } \\
\text { tro e } \\
\text { extensômetro } \\
\text { elétrico. }\end{array}$ & $\begin{array}{l}\text { Extensôme- } \\
\text { tro } \\
\text { tipo } \\
\text { "strain gage" }\end{array}$ & $\begin{array}{l}\text { Compressôme- } \\
\text { tro de base fixa } \\
\text { e extensômetro } \\
\text { digital. }\end{array}$ & - & $\begin{array}{l}\text { Extensômetro } \\
\text { tipo "clip gage". }\end{array}$ \\
\hline
\end{tabular}

Tabela 3: Dados gerais sobre os estudos experimentais escolhidos (continuação)

\begin{tabular}{|c|c|c|c|c|c|}
\hline \multicolumn{2}{|c|}{ PESQUISA } & $\begin{array}{c}\text { ARRUDA [6] e } \\
\text { SANTOS et [11] }\end{array}$ & $\begin{array}{c}\text { CABRAL } \\
{[19]}\end{array}$ & $\begin{array}{l}\text { BILESKY [49] e } \\
\text { RI FSKY }\end{array}$ & VASCONCELLOS \\
\hline \multirow{4}{*}{ MATERIAIS } & $\begin{array}{l}\text { Agregado } \\
\text { graúdo }\end{array}$ & Basalto e Dolomito & Granito & $\begin{array}{c}\text { Granito, Calcário e } \\
\text { Diabásio }\end{array}$ & Granito e Gnaisse \\
\hline & $\begin{array}{l}\text { Origem do } \\
\text { agregado }\end{array}$ & $\begin{array}{l}\text { Triângulo mineiro. } \\
\text { Basalto de } \\
\text { Uberlândia-MG e } \\
\text { Uberaba-MG; dolo- } \\
\text { mito de Patos de } \\
\text { Minas-MG). }\end{array}$ & Recife-PE & $\begin{array}{c}\text { Diabásio de Paulínia- } \\
\text { SP; granito de Itape- } \\
\text { cerica da Serra-SP; } \\
\text { calcário de } \\
\text { Araçariguama-SP. }\end{array}$ & $\begin{array}{l}\text { Granito de Tijucas- } \\
\text { SC, Gnaisse de Blu- } \\
\text { menau-SC e Gaspar- } \\
\text { SC. }\end{array}$ \\
\hline & Cimento & CP II E 32 & CP II E 40 & CP II E 40 & $\begin{array}{c}\text { CP IV } 32 \mathrm{Z} \text { e CP V } \\
\text { ARI }\end{array}$ \\
\hline & Aditivo & Sim & Sim & Sim & Sim \\
\hline \multirow{3}{*}{$\begin{array}{l}\text { DOSAGEM } \\
\text { CONCRETO }\end{array}$} & Em central? & Não, betoneira. & Não, betoneira. & Não & $\begin{array}{l}\text { Não, misturador } \\
\text { semiplanetário. }\end{array}$ \\
\hline & $\begin{array}{l}\text { Abatimento } \\
(\mathbf{m m})\end{array}$ & 60 a 200 & 100 a 105 & 110 a 120 & $150 \pm 30$ \\
\hline & $\begin{array}{c}\text { Relação } \\
\text { água/cimento }\end{array}$ & 0,35 a 0,53 & 0,45 a 0,75 & 0,30 a 0,90 & 0,46 a 0,71 \\
\hline
\end{tabular}




\begin{tabular}{|c|c|c|c|c|c|}
\hline & $\begin{array}{l}\text { fck nominal } \\
\text { (MPa) }\end{array}$ & 20,0 a 40,0 & 20,0 a 50,0 & 20,0 a 80,0 & - \\
\hline \multirow{6}{*}{ ENSAIOS } & Norma & \multicolumn{3}{|c|}{$\begin{array}{l}\text { ABNT NBR 5739: } 2007 \text { (compressão) e } \\
\text { ABNT NBR 8522: } 2008 \text { (módulo) }\end{array}$} & $\begin{array}{l}\text { ABNT NBR 5739: } \\
\text { 2014 (compressão) e } \\
\text { ABNT NBR 8522: }\end{array}$ \\
\hline & $\begin{array}{l}\text { Idade de ensaio } \\
\text { (dias) }\end{array}$ & $7,14,28$ e 56 & $3,7,28$ e 91 & 28 & 28 \\
\hline & Tipo de cura & $\begin{array}{l}\text { Câmara úmida até } \\
\text { desmoldagem, } \\
\text { seguida de cura sub- } \\
\text { mersa até data do } \\
\text { ensaio. }\end{array}$ & Câmara úmida. & $\begin{array}{c}\text { Cura úmida até } 7 \\
\text { dias de idade. } \\
\text { Ambiente do labora- } \\
\text { tório dos } 7 \text { aos } 28 \\
\text { dias. }\end{array}$ & $\begin{array}{l}\text { Imersão em tanque de } \\
\text { água com cal até a } \\
\text { idade de ensaio. }\end{array}$ \\
\hline & $\begin{array}{l}\text { Geometria dos } \\
\text { corpos-de-prova }\end{array}$ & \multicolumn{4}{|c|}{$\begin{array}{l}\text { Cilíndrico } \\
10 \times 20 \mathrm{~cm}\end{array}$} \\
\hline & $\begin{array}{l}\text { Tratamento da } \\
\text { superfície } \\
\text { de trabalho }\end{array}$ & Capeamento & Retificação & - & Retificação \\
\hline & $\begin{array}{l}\text { Medidores de } \\
\text { deformação }\end{array}$ & \multicolumn{2}{|c|}{ Extensômetro tipo "clip gage". } & - & $\begin{array}{l}\text { Compressômetro de } \\
\text { bases independentes. }\end{array}$ \\
\hline
\end{tabular}

Em seguida, os resultados obtidos aos 28 dias em cada uma das pesquisas abordadas para os ensaios de módulo de elasticidade (tangente inicial) e resistência à compressão, bem como demais parâmetros (abatimento, relação A/C, massa específica) foram extraídos, organizados, e tratados estatisticamente.

\subsection{Tratamento estatístico dos resultados}

Modelos de regressão (Equação 1) multivariáveis foram utilizados para estimar o módulo de deformação tangente inicial dos concretos $(E c i)$ em função da relação água/cimento $(A / C)$, do resultado do ensaio de abatimento $(A b)$, da massa específica $(\rho)$ e da resistência à compressão média $(f c m)$, ou da resistência característica à compressão $(f c k)$.

$$
\begin{aligned}
& E_{c i}=\beta_{0}+\beta_{1} \cdot A / C+\beta_{2} \cdot A b+\beta_{3} \cdot \rho+\beta_{4} \cdot f_{c}+\beta_{5} \cdot A / C^{2}+\beta_{6} \cdot A b^{2}+\beta_{7} \cdot \rho^{2}+\beta_{8} \cdot f_{c}^{2} \\
& +\beta_{9} \cdot A / C \cdot A b+\beta_{10} \cdot A / C \cdot \rho+\beta_{11} \cdot A / C \cdot f_{c}+\beta_{12} \cdot A b \cdot \rho+\beta_{13} \cdot A b \cdot f_{c}+\beta_{14} \cdot \rho \cdot f_{c}+\varepsilon
\end{aligned}
$$

$\mathrm{Na}$ Equação $1, \beta i$ são os coeficientes ajustados pelo método dos mínimos quadrados, $f c$ consiste ora no valor da resistência à compressão média $(f c m)$ ora na resistência característica à compressão $(f c k)$ e $\varepsilon$ é o erro aleatório. A qualidade dos ajustes foi avaliada por meio do coeficiente de determinação $\mathrm{R}^{2}$. Cada um dos modelos foi submetido à análise de variância (ANOVA), ao nível de 5\% de significância, possibilitando identificar os fatores e as interações entre esses que afetam de forma significativa os valores do Eci. O gráfico de Pareto foi utilizado para sintetizar os resultados da ANOVA.

O teste de Anderson-Darling (AD) foi utilizado para verificar a normalidade na distribuição dos resíduos, o gráfico de resíduos versus valores ajustado foi utilizado para verificar a homogeneidade dos resíduos e o gráfico de resíduos versus ordem foi utilizado para avaliar a independência dos resíduos, que consistem nas premissas de validação da ANOVA. Para o teste de AD, probabilidade $\mathrm{p}$ (p-valor) maior ou igual ao nível de significância adotado $(\alpha=0,05)$ implica na normalidade da distribuição dos resíduos, e na não normalidade em caso contrário. A transformada de Johnson foi utilizada quando não encontrada normalidade dos resíduos à priori. Dos 100 conjuntos de valores pareados das propriedades levantados da literatura $(A / C, A b, \rho$, $f c m, f c k$ e $E c i)$, apenas 60 destes contém informações da massa específica, e que, portanto, foram efetivamente utilizados nos modelos de regressão a várias variáveis.

Para os tipos de agregados, categorizados com $\alpha E$ igual a 0,$90 ; 1,00$ e 1,20, modelos de regressão a um parâmetro $(\beta 0)$ avaliados pela ANOVA (5\% de significância) foram utilizados na estimativa dos valores do módulo de elasticidade do concreto ora pelo valor médio da resistência à compressão conforme Equação 2 do 
CEB-FIP [41], ora pelo valor característico da propriedade, segundo a Equação 3, contida na versão de 2014 da NBR 6118 [7]; possibilitando avaliar se os $\alpha E$ normativos são efetivamente os valores mais adequados para o conjunto de resultados experimentais considerado nessa pesquisa.

$$
\begin{aligned}
& E_{c i}=\beta_{0} \cdot\left(f_{c m} / 10\right)^{1 / 3}+\varepsilon \\
& E_{c i}=\beta_{0} \cdot\left(f_{c k}\right)^{1 / 2}+\varepsilon
\end{aligned}
$$

O índice de concordância (Equação 4) de WILLMOT [52] foi utilizado para avaliar a concordância (proximidade) entre os valores experimentais provenientes da literatura, os estimados pelos modelos normativos e pelos modelos de regressão aqui propostos (Equações 2 e 3). $\mathrm{O}$ índice de concordância (IC) é uma quantidade adimensional e varia no intervalo ]0, 1[. IC igual a 1 implica na perfeita concordância entre a variável estimada e a observada.

$$
\mathrm{IC}=1-\frac{\sum_{i=1}^{N}\left(\tilde{E}_{c i}-E_{c i}\right)^{2}}{\sum_{i=1}^{N}\left(\left|\tilde{E}_{c i}-\bar{E}_{c i}\right|+\left|E_{c i}-\bar{E}_{c i}\right|\right)^{2}}
$$

Da Equação 4, $N$ consiste no número de valores pareados do módulo de elasticidade a compressão do concreto determinado experimentalmente $(E c i)$ e estimado ( $\tilde{E}_{c i}$ ) pelos modelos normativos, e $\bar{E}_{c i}$ é o valor médio dos módulos de elasticidade obtidos com esforço de compressão.

\section{RESULTADOS E DISCUSSÃO}

A Tabela 4 apresenta os valores médios $(\bar{x})$, os coeficientes de variação (CV), os menores (Mín) e os maiores (Máx) valores, e o intervalo de confiança da média ( $\mu-95 \%$ de confiabilidade) referentes às propriedades $A / C, A b(\mathrm{~mm}), \rho\left(\mathrm{kg} / \mathrm{m}^{3}\right), f c m(\mathrm{MPa}), f c k(\mathrm{MPa})$ e $E c i(\mathrm{MPa})$, levantadas na literatura citada. Cabe destacar que todas as propriedades apresentaram normalidade em suas distribuições, validando assim o uso dos intervalos de confiança determinados.

Tabela 4: Síntese dos resultados das propriedades determinadas da literatura.

\begin{tabular}{cccccc}
\hline PROPRIEDADE & $\overline{\boldsymbol{x}}$ & CV (\%) & MíN & MÁX & $\boldsymbol{\mu ~ ( 9 5 \% )}$ \\
\hline$A / C$ & 0,55 & 30,45 & 0,30 & 0,90 & $(0,50 ; 0,59)$ \\
$A b(\mathrm{~mm})$ & 111,98 & 20,22 & 60,00 & 200 & $(106,13 ; 117,83)$ \\
$\rho\left(\mathrm{kg} / \mathrm{m}^{3}\right)$ & 2395,83 & 2,86 & 2230 & 2550 & $(2378,13 ; 2413,53)$ \\
$f_{c m}(\mathrm{MPa})$ & 42,27 & 37,17 & 19,80 & 81,90 & $(38,21 ; 46,33)$ \\
$f_{c k}(\mathrm{MPa})$ & 39,96 & 40,79 & 18,53 & 80,27 & $(35,55 ; 44,37)$ \\
$E c i(\mathrm{MPa})$ & 35873 & 21,56 & 23500 & 53700 & $(33875 ; 37871)$ \\
\hline
\end{tabular}

Os resultados da Tabela 4 evidenciam os limites (extremo superior e inferior) das variáveis independentes consideradas, os quais devem ser respeitados na estimativa do módulo de elasticidade dos concretos pelos modelos de regressão multivariáveis aqui desenvolvidos. PACHECO [45], cujos resultados integram essa revisão, trabalhou com intervalo de abatimento 100 a $150 \mathrm{~mm}$ (média 115,03 mm) para concretos com fck nominal de $25 \mathrm{MPa}$ e intervalo de 85 a $120 \mathrm{~mm}$ (média 106,88 mm) para concretos com fck nominal de $30 \mathrm{MPa}$. Para a massa específica no estado fresco, o autor constatou, para os concretos de fck 25 e $30 \mathrm{MPa}$, médias de $2355,56 \mathrm{~kg} / \mathrm{m}^{3}$ e $2380,42 \mathrm{~kg} / \mathrm{m}$, respectivamente. 
Tendo em conta os intervalos de confiança para média das propriedades $\rho$ e A/C, bem como as afirmações de WU et al. [24] e AÏTCIN e MEHTA [27], conclui-se da Tabela 4 que o conjunto de trabalhos abordados neste estudo representa, em sua maioria, concretos ditos normais ou convencionais. No entanto, os valores mínimos e máximos observados, principalmente para o abatimento, fck e relação água cimento, sugerem a presença de concretos de alta resistência, dentro de uma amplitude considerável de resultados. Amplitude essa que também explica os altos coeficientes de variação alcançados nas variáveis em questão.

Nota-se também na Tabela 4 que a maior dispersão foi atingida para os valores da resistência característica à compressão $(f c k)$, tomados aos 28 dias de idade das misturas. Essa variação pode estar relacionada a vários fatores, sendo muitos deles os mesmos que interferem também nos módulos de deformação dos concretos. Conforme observado em trabalhos anteriores, a resistência à compressão é afetada pelo tempo de cura, grau de compactação das misturas, forma, textura e dimensão máxima do agregado graúdo, consumo de cimento, presença de aditivos e adições minerais, além de temperatura, umidade e demais condições/parâmetros de ensaio [13, 15, 20, 29].

Assim como o módulo de elasticidade do concreto, sua resistência é fortemente influenciada pela porosidade na ZTI pasta-agregado [15]. WU et al. [24] e VISHALAKSHI et al. [53], ressaltam, porém, que nos concretos convencionais o tipo de agregado não exerce tanta influência na resistência à compressão do compósito, uma vez que são a matriz da pasta de cimento (geralmente menos resistente) e a interface que sofrem com a presença precoce de microfissuras e, que ditam a falha do material. Para o contrário, a menor dispersão foi verificada para a propriedade de massa específica do concreto $(\rho)$. Quando comparada às demais propriedades dos concretos, nota-se que a massa específica foi apresentou, proporcionalmente, baixa amplitude entre resultados. Como consequência, têm-se a menor variabilidade.

Nota-se nos resultados experimentais abordados (Tabela 2 e Tabela 3), que os parâmetros de ensaio como dimensão dos corpos de prova, tempo de cura, preparação da superfície de trabalho e tipo de medidores de deformação se diferem entre as pesquisas. Com base no que foi elencado anteriormente, infere-se que, tanto a condição de umidade do concreto [13], quanto o tipo de instrumento para medição de deformações [34, 35], e ainda as dimensões dos espécimes [36], foram causadores da variabilidade observada nos resultados de Eci.

Optou-se por apresentar os modelos de regressão multivariáveis compostos apenas pelos termos considerados significativos pela ANOVA, uma vez que variações nos termos não significativos não impactariam de forma expressiva os valores estimados do módulo de elasticidade. A Equação 5 expressa o modelo de regressão multivariável para a estimativa do Eci dependente dos fatores $\mathrm{A} / \mathrm{C}, \mathrm{Ab}, \rho$ e fcm, e a Figura 5 ilustra os resultados da ANOVA (gráfico de Pareto) e da sua validação (normalidade, homogeneidade e independência dos resíduos).

$$
E_{c i}=37901+12379 \cdot \rho-12675 \cdot f_{c m}{ }^{2}+12454 \cdot \rho \cdot f_{c m}\left[R^{2}=87,21 \%\right]
$$

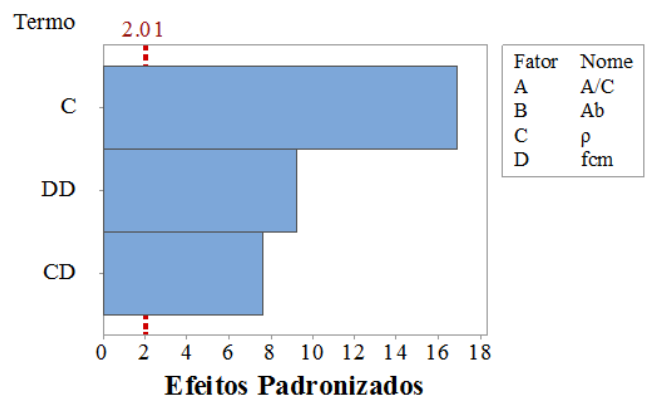

(a) Gráfico de Pareto

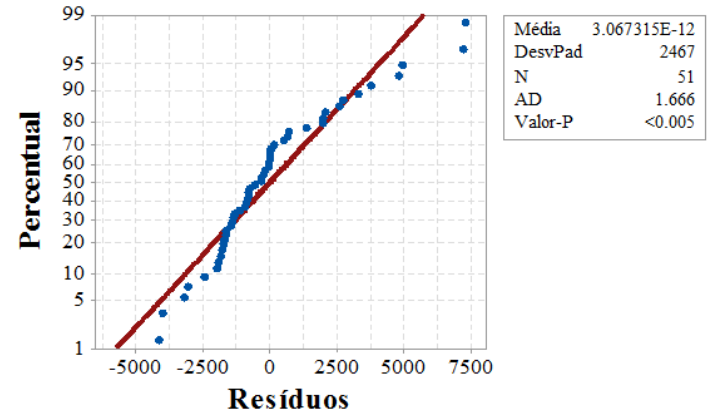

(b) Normalidade dos resíduos 


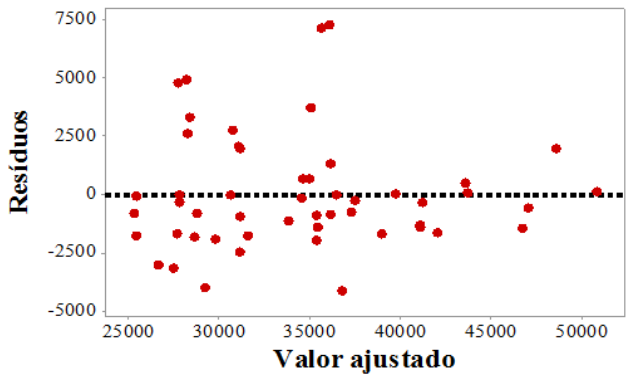

(c) Homogeneidade dos resíduos

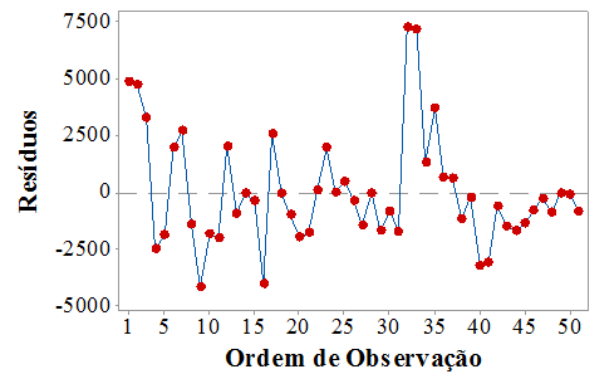

(d) Independência dos resíduos

Figura 6: Resultados de validação da ANOVA para modelo de regressão da Equação 5.

A Equação 5 foi gerada considerando 51 conjuntos pareados de valores das variáveis independentes $A / C$, $A b, \rho$ e $f c m$, destacando que apenas quatro outliers foram detectados com o uso desse modelo. $\mathrm{O}$ valor do coeficiente de determinação para esse ajuste foi de $87,21 \%$, evidenciando a boa precisão do mesmo na estimativa do módulo de elasticidade à compressão dos concretos abordados.

A Figura 5a ilustra o gráfico de Pareto com a ordem de significância dos termos. Para o modelo proposto pela Equação 5, a massa específica mostrou ser o fator mais significativo, seguido do quadrado da $\mathrm{fcm}$ e da interação entre $f c m$ e $\rho(\rho \cdot f c m)$. Cabe destacar a relação água/cimento (A/C) e o abatimento (Ab) não afetaram de forma significativa os valores do Eci quando considerada a resistência média a compressão dos concretos aqui estudados.

Interpretando a Equação 5, conclui-se que aumentos tanto nos valores da propriedade $\rho$ quanto na interação entre as propriedades $\rho$ e fcm refletem em aumentos nos valores de Eci. BARBOSA [46] também utilizou ANOVA, ao nível de 5\% de significância, para os fatores que afetaram significativamente os valores de Eci. Em seu gráfico de Pareto, o tipo de agregado se destaca como fator de maior influência na propriedade, seguido pelo nível de resistência do concreto. Embora a consistência da mistura (abatimento) não tenha alterado substancialmente os resultados de Eci encontrados pelo modelo retratado na Equação 5, nota-se resultados distintos em outros trabalhos. CABRAL [19], por exemplo, notou a partir de seu estudo experimental que os valores de Eci variaram de acordo com a consistência (abatimento) do concreto fresco, mesmo os concretos sendo produzidos com mesma relação A/C. O autor constatou ainda que o módulo tangente foi maior para concretos de consistência plástica quando comparado ao concreto autoadensável.

Com exceção dos quatro outliers detectados, nota-se das Figuras $5 \mathrm{c}$ e $5 \mathrm{~d}$ o atendimento à homogeneidade e à independência dos resíduos. Vale ressaltar que, a normalidade não foi atendida a priori $(\mathrm{p}$-valor $<0,05)$, mas que passou a ser atendida com a transformada de Johnson ( $\mathrm{p}$-valor $=0,818$ ), assim como ilustrado na Figura 6, validando assim os resultados da ANOVA do modelo de regressão. Destaca-se ainda que as premissas da ANOVA foram checadas no próximo modelo multivariável, assim como nos demais modelos para a estimativa do Eci dependente apenas da $f c m$ ou da $f c k$, sendo validada em todos os casos. 

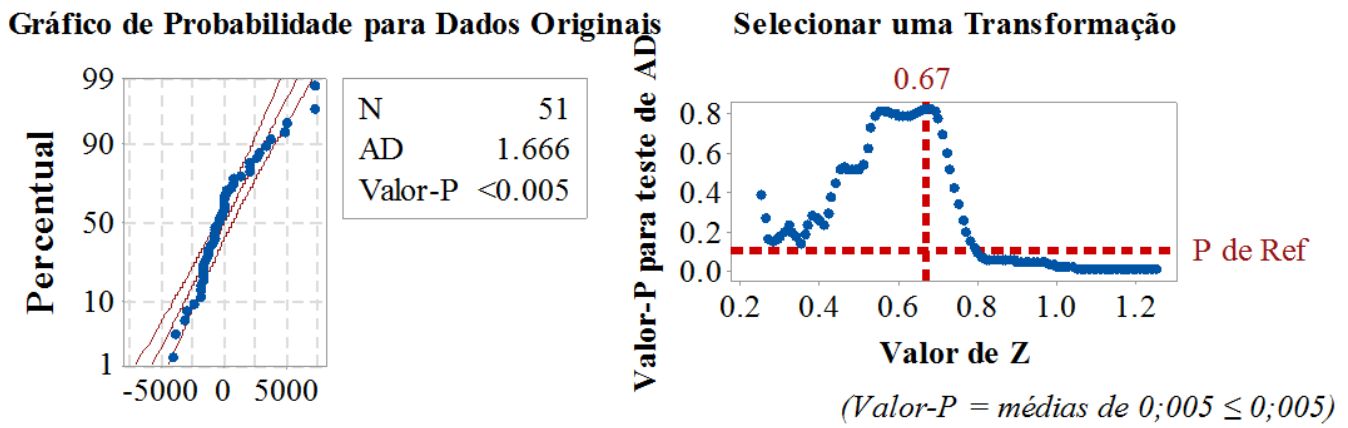

Gráfico de Probabilidade para Dados Transformados

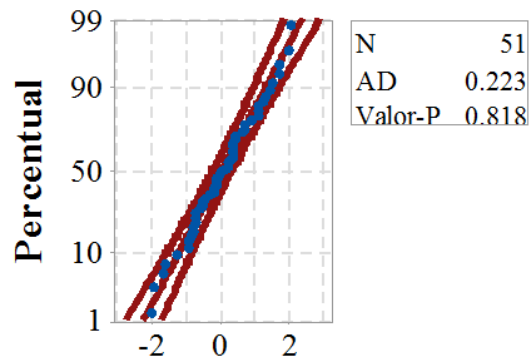

Valor-P para o Melhor Ajus te: 0.818095

Z para o Melhor Ajuste: 0.67

Melhor Tipo de Transformação: SU

A função de transformação é igual a

$-0.595366+1.02155 \times \operatorname{Asenh}((\mathrm{X}-1510.39) / 1367.10)$

Figura 7: Resultados da transformada de Johnson para a normalidade dos resíduos do modelo de regressão da Equação 5.

O modelo para a estimativa do Eci em função das variáveis independentes $A / C, A b, \rho$ e $f c k$ é expresso pela Equação 6, e os resultados da ANOVA (gráfico de Pareto) são ilustrados na Figura 7.

$$
E_{c i}=34723+16526 \cdot \rho+9642 \cdot A / C \cdot \rho+9736 \cdot \rho \cdot f_{c k}\left[R^{2}=71,96 \%\right]
$$

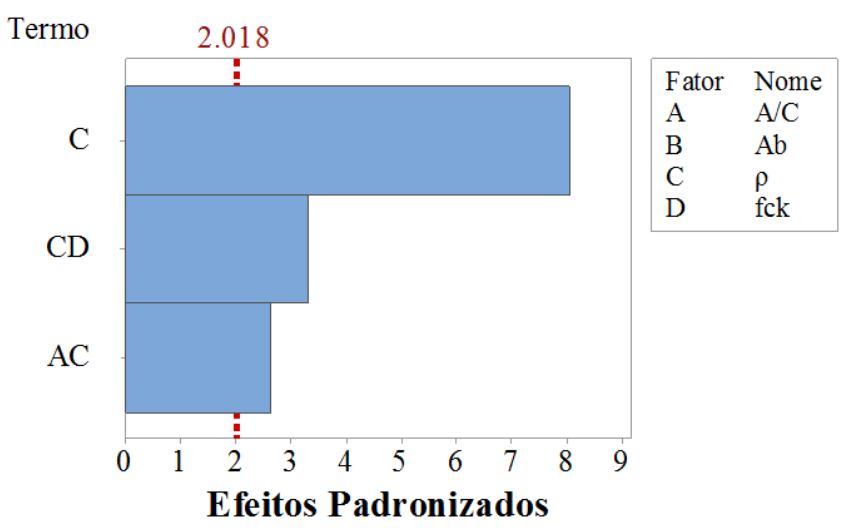

Figura 8: Gráfico de Pareto do modelo de regressão da Equação 6.

A Equação 6 foi gerada considerando-se 46 conjuntos pareados de valores das variáveis independentes $A / C, A b, \rho$ e $f c k$, cabendo destacar que nove outliers foram detectados com o uso desse modelo. O valor do coeficiente de determinação para esse ajuste foi de 71,96\%, o que também evidenciou uma boa precisão do modelo na estimativa de Eci. A interpretação da Equação 6 permite concluir que aumentos tanto de $\rho$ quanto para interação entre $\rho$ e $f c k$ refletiram em aumentos nos valores de $E c i$ para os concretos analisados. Assim como no modelo da Equação 5, a massa específica do concreto foi também o fator mais significativo na estimativa do $E c i$, e os fatores relação $\mathrm{A} / \mathrm{C}$ e abatimento também não foram considerados significativos.

Merece atenção o fato de que, dentre todos os quatro fatores abordados a massa específica foi considerada como o mais influente no módulo de elasticidade do concreto. Algo constado tanto quando se estima a propriedade com base na resistência à compressão média (Equação 5) quanto pela resistência característica (Equação 6) dos concretos. Vale lembrar que a influência da massa específica no módulo do concreto já é levada em consideração em códigos normativos internacionais [39, 40] e também em modelos de regressão 
propostos por outros pesquisadores [54]. Esse destaque observado para a massa específica do material, reitera a afirmação feita por HELENE [16], de que a resistência à compressão se constitui em apenas uma das variáveis das quais depende o módulo de elasticidade do concreto.

A Tabela 5 apresenta os resultados dos modelos de regressão baseados nos documentos normativos NBR 6118 [7] e CEB-FIP [41] considerando-se os tipos de agregado pertencentes à família do calcário $(\alpha E=0,9)$, do granito $(\alpha E=1,0)$ e do basalto $(\alpha E=1,2)$, bem como os valores dos coeficientes $\alpha E$ associados aos ajustes e os respectivos índices de concordância.

Tabela 5: Resultados dos modelos de regressão considerando os tipos de agregado na estimativa do Eci pelas normas NBR 6118 [7] (fck) e CEB-FIP [41] (fcm).

\begin{tabular}{clcccc}
\hline $\begin{array}{c}\boldsymbol{\alpha}_{\mathrm{E}} \\
\text { (normativo) }\end{array}$ & \multicolumn{1}{c}{ Modelos } & $\mathbf{R}^{2}(\%)$ & $\begin{array}{c}\text { p-valor } \\
\text { (ANOVA) }\end{array}$ & $\begin{array}{c}\boldsymbol{\alpha}_{\mathrm{E}} \\
\text { (modelos) }\end{array}$ & IC \\
\multirow{2}{*}{0,90} & $\mathrm{E}_{\mathrm{ci}}=23266,05 \cdot\left(\mathrm{f}_{\mathrm{cm}} / 10\right)^{1 / 3}$ & 57,77 & $<0,05$ (sign.) & 1,08 & 0,847 \\
& $\mathrm{E}_{\mathrm{ci}}=6062,94 \cdot\left(\mathrm{f}_{\mathrm{ck}}\right)^{1 / 2}$ & 59,87 & $<0,05$ (sign.) & 1,08 & 0,822 \\
\multirow{2}{*}{1,00} & $\mathrm{E}_{\mathrm{ci}}=21541,39 \cdot\left(\mathrm{f}_{\mathrm{cm}} / 10\right)^{1 / 3}$ & 51,25 & $<0,05$ (sign.) & 1,00 & 0,605 \\
& $\mathrm{E}_{\mathrm{ci}}=5771,95 \cdot\left(\mathrm{f}_{\mathrm{ck}}\right)^{1 / 2}$ & 45,84 & $<0,05$ (sign.) & 1,03 & 0,577 \\
\multirow{2}{*}{1,20} & $\mathrm{E}_{\mathrm{ci}}=22999,50 \cdot\left(\mathrm{f}_{\mathrm{cm}} / 10\right)^{1 / 3}$ & 45,56 & $<0,05$ (sign.) & 1,07 & 0,761 \\
& $\mathrm{E}_{\mathrm{ci}}=6386,54 \cdot\left(\mathrm{f}_{\mathrm{ck}}\right)^{1 / 2}$ & 57,04 & $<0,05$ (sign.) & 1,14 & 0,836 \\
\hline
\end{tabular}

Da Tabela 5, todos os modelos determinados foram considerados significativos (sign.) pela ANOVA. Os valores dos coeficientes de determinação foram todos inferiores aos valores do $\mathrm{R}^{2}$ obtidos com os modelos multivariáveis das Equações 4 e 5. Essa informação indica que a massa específica do concreto (fator de maior impacto nos modelos multivariáveis) deve ser levada em consideração para uma estimativa mais precisa dos valores do módulo de deformação tangente inicial do concreto, cabendo destacar que os maiores valores do índice de concordância também ocorreram nos modelos associados aos maiores valores do coeficiente de determinação.

Para os modelos da Tabela 5 baseados na norma NBR 6118 [7], importante destacar que foram considerados apenas os valores da $f c k$ entre 20 e $50 \mathrm{MPa}$, que consistem em aproximadamente $90 \%$ dos conjuntos de valores obtidos da literatura citada.

Nas Figuras 8 e 9 são apresentados os ajustes dos modelos da Tabela 5, os modelos das normas para os respectivos valores dos coeficientes $\alpha E$ e as nuvens de pontos experimentais obtidos da literatura.
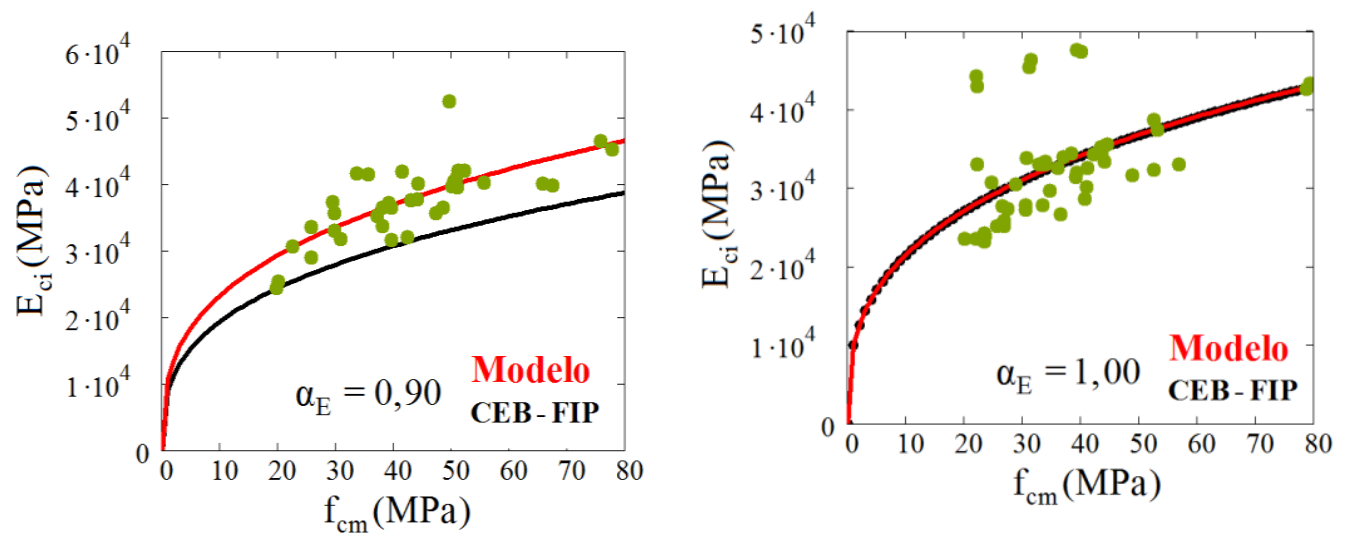


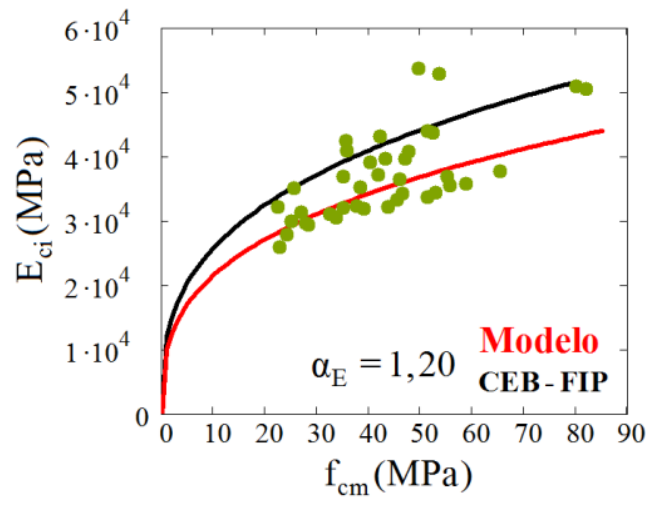

Figura 9: Dados experimentais, modelos de mínimos quadrados e o modelo da norma CEB-FIP [41] para a estimativa do Eci em função da fcm referente aos coeficientes $\alpha E$.
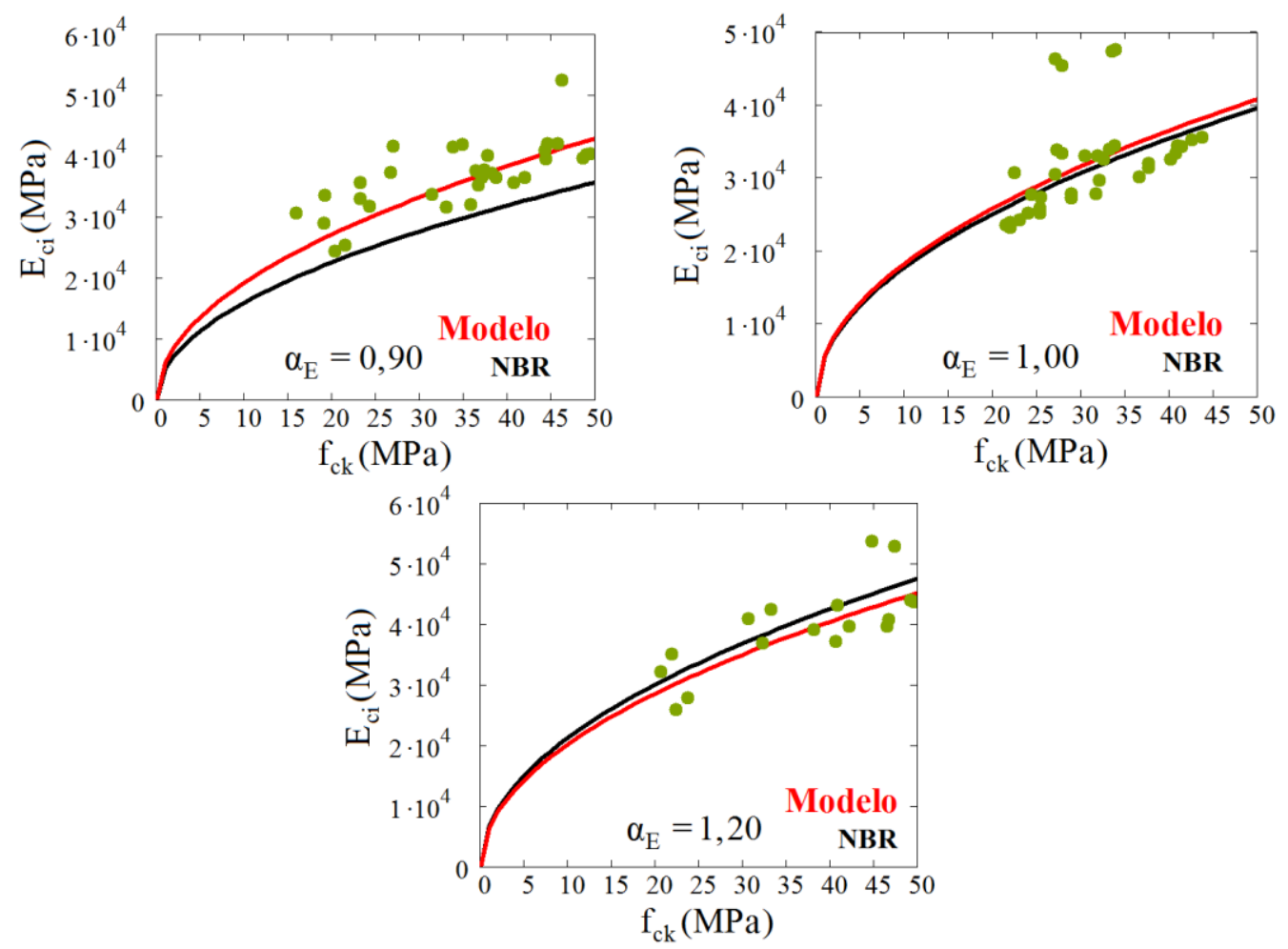

Figura 10: Dados experimentais, modelos de mínimos quadrados e o modelo da norma NBR 6118 [7] para a estimativa do $E c i$ em função da $f c k$ referente aos coeficientes $\alpha E$.

Da Tabela 5, Figura 8 e Figura 9, nota-se que o valor do coeficiente $\alpha E$ encontrado nos modelos para os concretos produzidos com agregados graúdos da classe do calcário foram superiores ao valor de 0,90 proposto tanto pela NBR 6118 [7] quanto pelo CEB-FIP [41]. Isso significa que as equações contidas nas duas normas, da forma como estão, fornecem valores subestimados para a propriedade Eci quando os novos coeficientes de ajuste, levantados com base na reunião de resultados experimentais deste trabalho, são inseridos.

Para a classe de agregados graúdos que engloba o granito e o gnaisse, os modelos forneceram valores de $\alpha E$ iguais $(\alpha E=1,00)$ ao proposto pelas normas em questão [7, 41]. Isso significa que os coeficientes de ajuste para a classe do agregado granito encontrados aqui estão em consonância com os já propostos nas referidas normas.

No caso dos concretos contendo agregado graúdo de basalto, os valores de $\alpha E$ fornecidos pelos modelos deste estudo se mostraram inferiores ao que consta na NBR 6118 [7] e no CEB-FIP [41] $(\alpha E=1,20)$, sendo essa diferença mais acentuada quando $E c i$ é dado em função da resistência média à compressão $(f c m)$ do concreto. Infere-se, com base nessa observação, que da maneira como está o coeficiente de 1,2 adotado para a 
família de agregados do basalto fornece valores superestimados para os concretos estudados neste trabalho.

$\mathrm{Na}$ pesquisa desenvolvida por BARBOSA [55], a equação normativa que forneceu maior proximidade com seus resultados experimentais de módulo de elasticidade (Eci) foi a do CEB-FIP [41], enquanto a equação proposta pela NB1[38]. ARAÚJO [37, 56] também encontrou maior proximidade de seus valores experimentais com o CEB-FIP [41], tratando, porém, do módulo de deformação secante (Ecs). Mesmo mais próximos e com menores variações em relação à aproximação fornecida por outros códigos, o autor afirma que o valores de Ecs para concretos contendo agregado graúdo da família do gnaisse foram superestimados pela norma em questão [41]. Para agregados da família do basalto e do calcário os valores de Ecs foram subestimados em relação aos experimentais.

No estudo de CABRAL [19], concluiu-se que os resultados fornecidos pelo CEB-FIP [41] superestimaram os valores experimentais, fornecendo valores superiores aos estimados também pelas normas NBR 6118 [7], ACI 318 [40] e DIN 1045 [43].

De uma forma geral, os modelos obtidos nesta pesquisa se mostraram mais conservadores do que o os modelos normativos $[7,41]$ para concretos produzidos com agregado graúdo da classe do calcário. Já para concretos contendo agregados graúdos de basalto, os modelos propostos pela NBR 6118 [7] e pelo CEB-FIP [41] podem ser considerados mais conservadores do que os verificados por meio deste trabalho.

A progressão nos valores dos coeficientes de ajuste, no entanto, foi mantida, o que confirma as ponderações encontradas na literatura $[13,21,29]$ de que agregados conhecidos por serem mais rígidos dão origem a concretos também com maiores valores do módulo de elasticidade.

Além de não levarem em consideração a massa específica das misturas (considerada um fator de grande significância neste trabalho), os modelos obtidos com baixos valores para o coeficiente de determinação $\mathrm{R}^{2}$ (Tabela 5) também podem ser atrelados ao fato de que nenhuma das equações empíricas contidas nas normativas mencionadas até então considera as características da ZTI pasta-agregado, nem o estado de umidade dos corpos de prova durante os testes, por exemplo [15]. Como confirmado pela literatura, as particularidades atribuídas à região da interface entre os agregados e a matriz [28, 31, 32] exercem grande influência na deformabilidade do concreto.

A Tabela 6 apresenta os índices de concordância (IC) obtidos com o uso dos modelos normativos que desconsideram os tipos de agregado na estimativa dos valores dos módulos de elasticidade a compressão dos concretos.

Tabela 6: Índices de concordância (IC) obtidos pelos modelos normativos que desconsideram os tipos de agregados

\begin{tabular}{cl}
\hline NORMAS & IC \\
\hline NB1 (versão 1978) [38] & 0,137 \\
NBR 6118 (versão 2007) [8] & 0,168 \\
EUROCODE 2 - EN 1992-1-1 (versão 2004) [42] & 0,676 \\
DIN - 1045 (versão 2001) [43] & 0,149 \\
\hline
\end{tabular}

Da Tabela 6, nota-se que o maior valor do IC foi proveniente do EUROCODE 2 [42], sendo pequena a concordância das demais normas com relação aos valores do módulo de elasticidade obtidos experimentalmente. Ainda assim, o IC da norma europeia foi superior a IC de apenas um dos modelos da Tabela 5 o que evidencia a importância de se considerar a natureza do agregado graúdo quando se utiliza modelos de uma única variável $(f c k$ ou $f c m)$.

\section{CONCLUSÕES}

Este trabalho propôs uma comparação entre resultados de estudos experimentais para o módulo de elasticidade (Eci) de concretos contendo agregados graúdos de diversas origens, e destes com os modelos propostos pela versão vigente da norma brasileira, por versões anteriores, e por códigos estrangeiros. Seu principal objetivo consistiu em encontrar os melhores ajustes para o coeficiente relacionado à mineralogia do agregado graúdo além de evidenciar a importância de outras variáveis na definição do módulo do concreto. Diante dos 
resultados obtidos, podem ser tomadas as seguintes conclusões:

- Os modelos obtidos para expressar o Eci dos concretos em função da relação A/C, abatimento $(A b)$, massa específica $(\rho)$ e resistência à compressão (ora $f c m$, ora $f c k$ ) aos 28 dias apresentaram boa precisão, com coeficiente de determinação $\left(\mathrm{R}^{2}\right)$ na ordem de 70 e $90 \%$. Os índices de concordância (IC) obtidos com o uso dos modelos normativos que desconsideram o tipo de agregado na estimativa dos valores de $E c i$ foi reduzido consideravelmente, evidenciando a importância em se considerar a natureza do agregado graúdo quando se utiliza modelos de uma única variável $(f c k$ ou $f c m)$.

- Entre todas propriedades analisadas, a massa específica ( $\rho$ ) foi a que exerceu maior influência nos valores de $E c i$ dos concretos obtidos aos 28 dias de idade e, portanto, não deve ser deixada de fora nas equações que estimam a propriedade. Modelos que não continham a variável tiveram sua qualidade significativamente reduzida.

- Em conformidade com a literatura, verificou-se que aumentos nos valores da massa específica ( $\rho$ ) e da resistência à compressão $(f c m$ ou $f c k)$ dos concretos refletem em maiores valores de Eci. Porém, ao contrário do que foi observado por alguns autores, os resultados experimentais de $E c i$ abordados neste estudo não foram significativamente influenciados pela relação $\mathrm{A} / \mathrm{C}$, nem pelo abatimento $(A b)$ das misturas.

- A progressão nos valores dos coeficientes atrelados a mineralogia do agregado graúdo $(\alpha E)$, reajustados neste trabalho, confirma as ponderações encontradas na literatura de que agregados conhecidos por serem mais rígidos dão origem a concretos também com maiores valores do módulo de elasticidade.

- A variabilidade encontrada nos resultados pode ser atribuída a inúmeros fatores. O principal deles consiste no fato de que nenhuma das equações normativas tratadas considera o concreto como material compósito e, sobretudo, não contempla as particularidades da ZTI pasta-agregado das misturas. A maioria dos concretos tratados aqui se enquadram na classe dos concretos ditos normais ou convencionais, e que, segundo a literatura, têm seu comportamento e falha regidos principalmente pela região da interface entre as fases. Acredita-se que a diversidade nos parâmetros de ensaio (dimensões dos espécimes, tratamento de superfície, condição de cura e umidade antes do ensaio, medidor de deformação) dos trabalhos abordados também tenha contribuído para a alta variabilidade.

- Quando comparados aos modelos normativos, os valores do coeficiente $\alpha \mathrm{E}$ reajustados para agregados graúdos da classe do calcário foram superiores ao proposto tanto pela NBR 6118 quanto pelo CEB-FIP. Isso significa que as equações contidas nas duas normas, da forma como estão, fornecem valores subestimados para os resultados de Eci aqui encontrados e, portanto, mais conservadores. No entanto, no caso dos concretos contendo agregado graúdo de basalto, os valores de $\alpha \mathrm{E}$ reajustados deste estudo se mostraram inferiores ao 1,2 que consta nas duas normas, sendo superestimados, o que vai na direção oposta à segurança nos projetos. Para a classe do granito e gnaisse, os modelos reajustados estão em consonância com os já propostos nas referidas normas.

\section{AGRADECIMENTOS}

Agradecimentos à Coordenação de Aperfeiçoamento de Pessoal de Nível Superior - CAPES pelo fomento a esta pesquisa e a coordenação do Programa de Pós-graduação em Engenharia Civil - PPGECiv/UFSCar pelo apoio.

\section{BIBLIOGRAFIA}

[1] KALRA, M., MEHMOOD, G., "A Review paper on the Effect of different types of coarse aggregate on Concrete", Materials Science and Engineering, v. 431, 2018.

[2] GIRARDI, R., DAL MOLIN, D.C., RECENA, F.A.P., "Portland Cement Concrete Deformation Modulus: Influence of Paste Volume", ACI Materials Journal, v. 117, n.1, Jan. 2020.

[3] PIASTA, W., GÓRA, J., BUDZYNSKI, W., "Stress-strain relationships and modulus of elasticity of rocks and of ordinary and high-performance concretes", Construction and Building Materials, v. 153, pp. 728-739, 2017.

[4] MARCHI, R.D., Estudo sobre a variabilidade do módulo de deformação do concreto associada a fatores intrínsecos à produção do material, Dissertação de M.Sc, Universidade de São Paulo, São Paulo, SP, Brasil, 2011. 
[5] ZHOU, F.P., LYDON, F.D., BARR, B.I.G., "Effect of coarse aggregate on elastic modulus and compressive strength of high performance concrete", Cement and Concrete Research, v. 25, n.1, pp. 177-186, 1995.

[6] ARRUDA, A.M., Módulo de elasticidade de concretos produzidos com formações rochosas do triângulo mineiro, Dissertação de M.Sc, Universidade Federal de Uberlândia, Uberlândia, MG, 2013.

[7] ASSOCIAÇÃO BRASILEIRA DE NORMAS TÉCNICAS. NBR 6118: Projeto de estruturas de concreto - procedimento, Rio de Janeiro, 2014.

[8] ASSOCIAÇÃO BRASILEIRA DE NORMAS TÉCNICAS. NBR 6118: Projeto de estruturas de concreto - procedimento, Rio de Janeiro, 2007.

[9] CABRAL, L., MONTEIRO, E., HELENE, P., "Análise comparativa do módulo de elasticidade calculado segundo diferentes normas", ALCONPAT, v. 4, n.2, pp. 144-160, Mai./Ago. 2014.

[10] BARBOSA, R.A., ALVARENGA, R.C.S., CARVALHO JÚNIOR, A.N., et al., "Análise comparativa de métodos de obtenção do módulo de elasticidade para concreto preparado com areias natural e artificial", Ciência \& Engenharia, v. 24, n. 1, pp. 151-161, 2015.

[11] SANTOS, A.C., ARRUDA, A.M., SILVA, T.J., et al., "Estudo comparativo entre valores teóricos e resultados experimentais de módulo de elasticidade de concretos produzidos com diferentes tipos de agregado graúdo", Ambiente Construído, v. 17, n.3, pp. 249-262, Jul./Set. 2017.

[12] VASCONCELOS, A.C., GIAMMUSSO, S.E., "O misterioso módulo de elasticidade", TQS - Artigos, fev. 2009. Disponível em: http://www.tqs.com.br/suporte-e-servicos/biblioteca-digital-tqs/89-artigos/199-omisterioso-modulo-de-elasticidade?format=pdf. Acesso em: 24 julho 2019.

[13] NEVILLE, A.M., Propriedades do concreto, 5. ed., Porto Alegre: Bookman, 2016.

[14] ASSOCIAÇÃO BRASILEIRA DE NORMAS TÉCNICAS. NBR 8522: Concreto - Determinação dos módulos estáticos de elasticidade e de deformação à compressão, Rio de Janeiro, 2017.

[15] MEHTA, P.K., MONTEIRO, P.J.M. CONCRETO. Microestrutura, propriedades e materiais, 2. ed., São Paulo: IBRACON, 2014.

[16] HELENE, P.R.L., Relatório à ABCP: Estudo da variação do módulo de elasticidade do concreto com a composição e características do concreto fresco e endurecido, Departamento de Engenharia de Construção Civil: Escola Politécnica, Universidade de São Paulo, São Paulo, SP, Brasil, 1998.

[17] BROOKS, J.J., "Elasticity of Concrete", In: BROOKS, J.J., Concrete and Masonry Movements, chapter 4, Elsevier Inc., 2015.

[18] SOUZA, P.S.L, DAL MOLIN, D.C.C, PICANÇO, M.S., et al., "Avaliação do módulo de elasticidade em concreto com metacaulim de alta reatividade, proveniente de rejeito industrial", Revista Matéria, v. 20, n. 4, pp. 982-991, 2015.

[19] CABRAL, L.M.C., Análise comparativa do módulo de elasticidade calculado segundo diferentes normas, Dissertação de M.Sc, Universidade Católica de Pernambuco, Recife, PE, Brasil, 2014.

[20] MONTEIRO, P.J.M., HELENE, P.R.L., KANG, S.H., "Designing concrete mixtures for strength, elastic modulus and fracture energy", Materials and Structures, v. 26, pp. 443-452, 1993.

[21] COUNTO, U.J., "The effect of the elastic modulus of the aggregate on the elastic modulus, creep and creep recovery of concrete", Magazine of Concrete Research, v. 16, n. 48, 1964.

[22] STOCK, A.F., HANNANTT, D.J., "The effect of aggregate concentration upon the strength and modulus of elasticity of concrete", Magazine of Concrete Research, v. 31, n. 109, 1979.

[23] NEVILLE, A.M., "Aggregate Bond and Modulus of Elasticity of Concrete", ACI Materials Journal, v. 94, n.1, Jan./Feb. 1997.

[24] WU, K.R., CHEN, B., YAO, W., et al., "Effect of coarse aggregate type on mechanical properties of high-performance concrete", Cement and Concrete Research, v. 31, pp. 1421-1425, 2001.

[25] NETO, B.B.P, OLIVEIRA, D.R.C, RAMOS, D., "Efeitos do tipo, tamanho e teor de agregado graúdo no módulo de deformação do concreto de alta resistência", Revista Matéria, v. 16, n. 2, pp. 690-702, 2011.

[26] BEUSHAUSEN, H., DITTMER, T., "The influence of aggregate type on the strength and elastic modulus of high strength concrete", Construction and Building Materials, v. 74, pp. 132-139, 2015.

[27] AÏTCIN, P.C., MEHTA, P.K., "Effect of Coarse-Aggregate Characteristics on Mechanical Properties of High-Strength Concrete", ACI Materials Journal, v. 87, n.2, Mar./Apr. 1990. 
[28] YILDIRIM, H., SENGUL, O., "Modulus of elasticity of substandard and normal concretes", Construction and Building Materials, v. 25, pp. 1645-1652, 2011.

[29] ZHOU, Y., GAO, J., SUN, Z., et al., "A fundamental study on compressive strength, static and dynamic elastic moduli of young concrete", Construction and Building Materials, v. 98, pp. 137-145, 2015.

[30] HONG, L., GU, X., LIN, F., "Influence of aggregate surface roughness on mechanical properties of interface and concrete", Construction and Building Materials, v. 65, pp. 338-349, 2014.

[31] SCRIVENER, K., GARTNER, E., "Microstructural Gradients in Cement Paste Around Aggregate Particles", In: Proceedings of MRS Fall meeting MRS Fall Meeting: Symposium R - Bonding in Cementitious Composites, pp. 77-85, Boston, 1988.

[32] ZIJIAN, J., HAN, Y., ZHANG, Y., et al., "Quantitative characterization and elastic properties of interfacial transition zone around coarse aggregate in concrete”, Cementitious Materials, v. 32, pp. 838-844, 2017.

[33] PAULON, V.A., DAL MOLIN, D., MONTEIRO, P.J.M, "Statistical Analysis of the Effect of Mineral Admixtures on the Strength of the Interfacial Transition Zone”, Interface Science, v. 12, pp. 399-410, 2004.

[34] MONTIJA, F.C., Aspectos da variabilidade experimental do ensaio de módulo de deformação do concreto, Dissertação de M.Sc, Universidade de São Paulo, São Paulo, SP, 2007.

[35] ARAÚJO, S.S., GUIMARÃES, G.N., GEYER, A.L.B, "Influência do tipo de medição na determinação do módulo estático de elasticidade do concreto", Revista IBRACON de Estruturas e Materiais, v. 5, pp. 555575, Out. 2012.

[36] MARTINS, D.G., Influência do tamanho do corpo de prova nos resultados de ensaios de módulo de deformação e resistência à compressão e suas correlações para concretos produzidos em Goiânia-GO, Dissertação de M.Sc, Universidade Federal de Goiás, Goiânia, GO, 2008.

[37] ARAÚJO, J.M., "O módulo de deformação longitudinal do concreto", Teoria e Prática na Engenharia Civil, n. 1, pp. 9-16, 2000.

[38] ASSOCIAÇÃO BRASILEIRA DE NORMAS TÉCNICAS. NB 1: Projeto e execução de obras de concreto armado - procedimento, Rio de Janeiro, 1978.

[39] AMERICAN CONCRETE INSTITUTE. ACI 318-05: Building Code Requirements for Structural Concrete and Commentary, Farmington Hills, 2005.

[40] AMERICAN CONCRETE INSTITUTE. ACI 318-19: Building Code Requirements for Structural Concrete and Commentary, Farmington Hills, 2019.

[41] FÉDERATION INTERNATIONALE DU BETÓN. CEB-FIP Model Code 2010: Final draft, Lausanne, 2012.

[42] EUROPEAN COMMITTEE FOR STANDARDIZATION. EN 1992-1-2 Eurocode 2: Design of concrete structures - Part 1-1: General rules and rules for buildings, Brussels, 2004.

[43] DEUTCHES INSTITUTE FÜR NORMUNG. DIN 1045-2: Plain, reinforced and prestressed concrete structures - Part 2: Specification, properties, production and conformity of concrete, Berlin, 2001.

[44] NUNES, F.W.G., Avaliação da resistência e do módulo de elasticidade de concretos usados no Rio de Janeiro, Dissertação de M.Sc, Universidade Federal do Rio de Janeiro, Rio de Janeiro, RJ, Brasil, 2005.

[45] PACHECO, R.F.R., Análise do módulo de elasticidade e resistência à compressão de concretos produzidos em centrais na Grande Vitória, Dissertação de M.Sc, Universidade Federal do Espírito Santo, Vitória, ES, Brasil, 2006.

[46] BARBOSA, I.L.S., Influência dos Agregados Graúdos da Região de Goiânia no Módulo de Deformação Tangente Inicial do Concreto, Dissertação de M.Sc, Universidade Federal de Goiás, Goiânia, GO, Brasil, 2009.

[47] ALMEIDA, S.M., Análise do módulo de elasticidade estático e dinâmico do concreto de cimento Portland através de ensaios de compressão simples e de frequência ressonante, Dissertação de M.Sc, Universidade Federal de Minas Gerais, Belo Horizonte, MG, Brasil, 2012.

[48] LEAL, A.C.F.S., Investigação experimental do módulo de elasticidade nos concretos produzidos em Brasília, Dissertação de M.Sc, Universidade de Brasília, Brasília, DF, Brasil, 2012.

[49] BILESKY, P.C., Contribuição aos estudos do módulo de elasticidade do concreto, Dissertação de M.Sc, Instituto de Pesquisas Tecnológicas do Estado de São Paulo, São Paulo, SP, Brasil, 2016. 
[50] BILESKY, P., HELENE, P., SBRIGHI NETO, C., et al., "Influência da natureza petrográfica do agregado graúdo no módulo de elasticidade do concreto", In: Anais do $60^{\circ}$ Congresso Brasileiro do Concreto CBC2018, Foz do Iguaçu, Set. 2018.

[51] VASCONCELLOS, A.T., Estudo da variabilidade do módulo de elasticidade de concretos produzidos com diferentes tipos de agregados graúdos, Dissertação de M.Sc, Universidade Federal de Santa Catarina, Florianópolis, SC, Brasil, 2018.

[52] WILLMOT, C.J., "Some Comments on the Evaluation of Model Performance", Bulletin of the American Meteorological Society, v. 63, pp. 1309-1313, 1982.

[53] VISHALAKSHI, K.P., REVANTHI, V., REDDY, S.S., "Effect of type of coarse aggregate on the strength properties and fracture energy of normal and high strength concrete", Engineering Fracture Mechanics, v. 194, pp. 52-60, 2018.

[54] NOGUCHI, T., TOMOSAWA, F., NEMATI, K.M., "A Practical Equation for Elastic Modulus of Concrete”, ACI Structural Journal, v. 106, n.5, Sep./Oct. 2009.

[55] BARBOSA, A.H., Contribuição ao estudo sobre a obtenção do módulo de elasticidade do concreto utilizando modelagem micromecânica, Tese de D.Sc, Universidade Federal de Pernambuco, Recife, PE, Brasil, 2010.

[56] ARAÚJO, J.M., "Modelos para previsão do módulo de deformação longitudinal do concreto: NBR-6118 versus CEB", Teoria e Prática na Engenharia Civil, n. 12, pp. 81-91, 2008.

\section{ORCID}

Cleber Eduardo Fernandes Leal

https://orcid.org/0000-0001-8280-0447

Guilherme Aris Parsekian

https://orcid.org/0000-0002-5939-2032

Fernanda Giannotti da Silva Ferreira

https://orcid.org/0000-0003-3222-1388

André Luis Christoforo

https://orcid.org/0000-0002-4066-080X 